Alessandra Pinheiro Costa Nascimento

\title{
PROJETO E DESENVOLVIMENTO DE UM CICLO ERGÔMETRO PARA MEMBROS SUPERIORES E INFERIORES
}

Dissertação apresentada ao Programa de Pós-Graduação Interunidades Bioengenharia - Escola de Engenharia de São Carlos/ Faculdade de Medicina de Ribeirão Preto/ Instituto de Química de São Carlos da Universidade de São Paulo, como parte dos requisitos para obtenção do título de Mestre em Bioengenharia.

Orientador: Prof. Dr. Orivaldo Lopes da Silva

São Carlos

2004 


\title{
DEDICATÓRIA
}

\begin{abstract}
A meus queridos pais, meus maiores exemplos de amor.
\end{abstract}

A meu marido Marcos, quero agradecer o amor, carinho e compreensão sempre presentes em nossas vidas.

A meu filho Arthur, fruto do nosso amor e razão de todo meu esforço. 


\section{AGRADECIMENTOS}

A Deus, que nos protege em todos os momentos.

Ao Prof. Dr. Orivaldo Lopes da Silva agradeço imensamente pela orientação e amizade.

Ao Prof. Dr. José Carlos Pereira sou grata pelo empenho em nos ajudar nas horas difíceis.

Ao Prof. Dr. Antônio Carlos Shimano pela oportunidade de começar e incentivo em prosseguir este trabalho.

Aos amigos José Cláudio P. de Azevedo e Luís Carlos Neves que desde o primeiro momento sempre me incentivaram e nunca pouparam esforços para que cada obstáculo fosse vencido na concretização deste projeto.

Aos funcionários do LAMAFE, Sr. Adão Santos Bouzan e Sr. José Carlos Risardi.

Ao chefe do Departamento de Metrologia Benedito di Giacomo agradeço por disponibilizar seu laboratório. Obrigado Fabrício Tadeu Paziani pela contribuição nos cálculos.

Ás secretárias de pós-graduação, Janete, Teresinha e Melaine.

A uma amiga muito especial, que como uma irmã, me acolheu e me acompanhou durante esses dois anos. A você Ana Cristina Kodama, ofereço minha eterna amizade.

Agradeço a você Tati, pela pessoa especial que é e por sempre me acolher com toda alegria do mundo.

Aos colegas pós-graduandos, Elizete, Paulo, Thais, Célio, Emerson, Ana Paula, vou sentir saudades. 


\section{RESUMO}

NASCIMENTO, A. P. C. Projeto e desenvolvimento de um ciclo ergômetro para membros superiores e inferiores. Dissertação de Mestrado, Alessandra Pinheiro Costa Nascimento.

Considerando que a maioria das clínicas de reabilitação física possui um ciclo ergômetro de uso restrito a membros inferiores, e que o ciclo ergômetro para membros superiores é ainda pouco comercializado e de alto custo, longe do alcance de muitos profissionais envolvidos na reabilitação em nosso país, avaliou-se a necessidade de desenvolver um equipamento que suprisse ambas necessidades. No presente estudo, um aparelho relativamente simples e de baixo custo, capaz de proporcionar meios para o exercício rotativo dos membros superiores e inferiores simultaneamente, foi projetado e construído com materiais de fácil obtenção e preço acessível. O ciclo ergômetro foi confeccionado e calibrado após a adaptação de um torquímetro, onde as medidas foram registradas por um sistema para medição de torque em eixos rotativos por meio de telemetria. Foram realizadas a calibração estática e avaliação dinâmica dos pedais e manípulos, onde os resultados demonstraram que o equipamento desenvolvido é capaz de realizar movimentos independentes de rotação dos membros inferiores ou superiores, isoladamente ou de forma conjunta, permitindo potencializar e ampliar o leque de benefícios gerados pelos aparelhos isolados. Este equipamento poderá ser útil na reabilitação de pacientes com patologias diversas como também para a realização de testes de esforços físicos nos departamentos de reabilitação e academias de ginástica.

Palavras-chave: ciclo ergômetro, calibração, reabilitação. 
NASCIMENTO, A. P. C. Project and enviroment of the cycle ergometer for upper limbs and lower limbs. Master Degree Dissertation. Alessandra Pinheiro Costa Nascimento.

Considering that most of the physical rehabilitation clinics has a cycle ergometer which use is restrict to the lower limbs and that the cycle ergometer for upper limbs is still a little commercialized and high cost, out of the possibilities of many professionals involved in rehabilitation in our country, it was evaluated the necessity of developing equipment that supplied both necessities. In the present study, a relatively simple and low cost device able to provide ways to the rotatory exercise of both upper and lower limbs simultaneously was projected and constructed with easily obtained accessible price materials. The cycle ergometer was built and gauged after the adaptation of a torquimeter, where the measures were recorded by a rotatory axis torque measure system through telemetry. It was accomplished a static and dynamic calibration on pedals and handles, which results showed that the developed equipment is able to accomplish independent rotation movements for both upper and lower limbs, isolately or entirely, allowing to pontentialize and amplify the list of benefits generated by the isolate devices. This equipment may be useful to rehabilitate patients bearing diverse pathologies as well as to the accomplishment of physical effort tests in rehabilitation departments and gyms.

Keywords: cycle ergometer, calibration, rehabilitation. 


\section{LISTA DE FIGURAS}

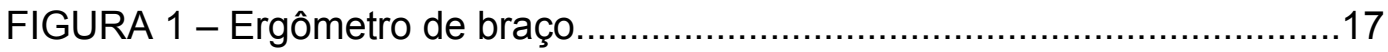

FIGURA 2 -“Saratoga Spirit 690", bicicleta para braços e pernas....................19

FIGURA 3 -"Pro II power trainer" para membros superiores e inferiores..........20

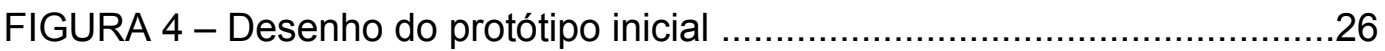

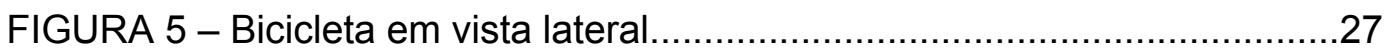

FIGURA 6 - Garfo de sustentação do disco de inércia e torquímetro ...............29

FIGURA 7 - Dispositivo de graduação de resistência ......................................30

FIGURA 8 - Bicicleta em vista fronto lateral... ……..................................... 31

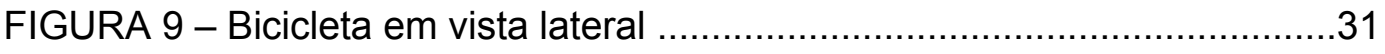

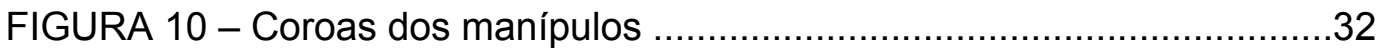

FIGURA 11 - Fixações do cubo e da catraca de marcha ..................................33

FIGURA 12 - Lateralização da coluna regulável ............................................34

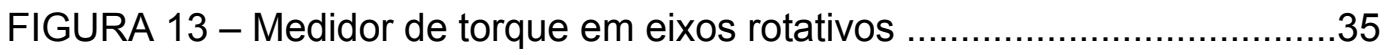

FIGURA 14 - Medidor de torque em eixos rotativos .....................................35

FIGURA 15 - Medidor de valores com suporte para bateria ............................36

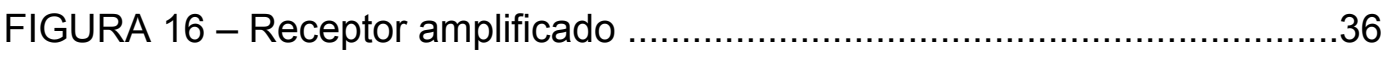

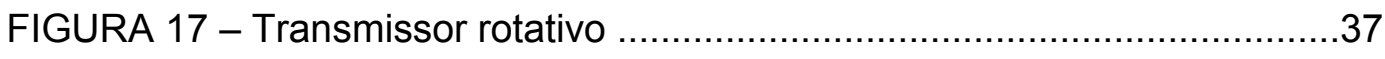

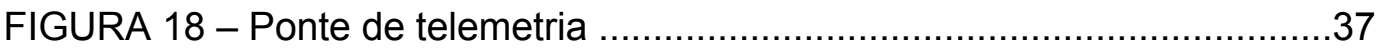

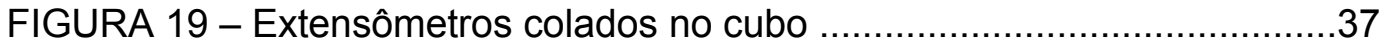

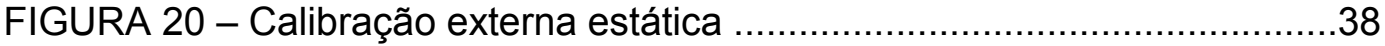

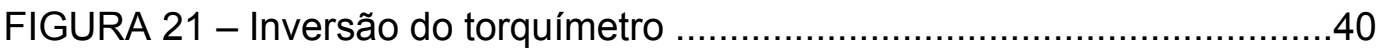

FIGURA 22 - Versão final do ciclo ergômetro em vista lateral.........................42

FIGURA 23 - Calibração externa estática.......................................................

FIGURA 24 - Apresenta o torque da calibração externa estática......................44

FIGURA 25 - Torque gerado na primeira roda livre (maior).............................46

FIGURA 26 - Torque gerado na segunda roda livre ........................................47

FIGURA 27 - Torque gerado na terceira roda livre........................................47

FIGURA 28 - Torque gerado na quarta roda livre............................................48

FIGURA 29 - Torque gerado na quinta roda livre .......................................48

FIGURA 30 - Torque gerado na sexta roda livre......................................... 
FIGURA 31 - Calibração estática dos pedais .50

FIGURA 32 - Força desenvolvida nos manípulos utilizando a primeira roda livre (maior)... .51

FIGURA 33 - Força desenvolvida nos manípulos utilizando a segunda roda livre FIGURA 34 - Força desenvolvida nos manípulos utilizando a terceira roda livre

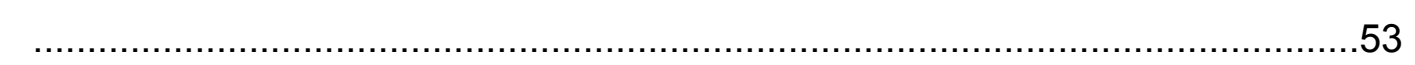

FIGURA 35 - Força desenvolvida nos manípulos utilizando a quarta roda livre .54

FIGURA 36 - Força desenvolvida nos manípulos utilizando a quinta roda livre .55

FIGURA 37 - Força desenvolvida nos manípulos utilizando a sexta roda livre

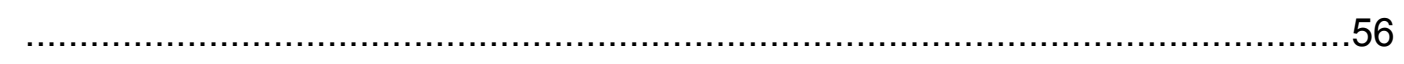

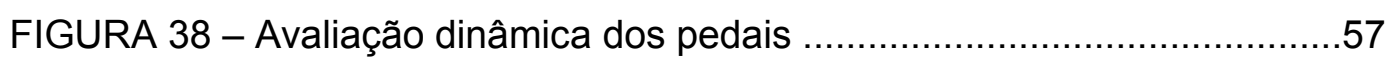

FIGURA 39 - Paciente tetraplégico exercitando em ergômetro de braço com

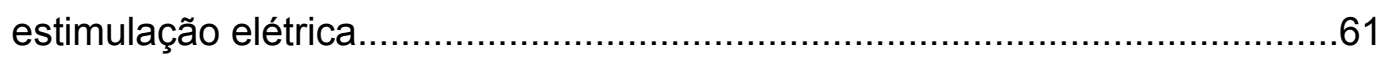

FIGURA 40 - Ergômetro de cadeira de rodas (wheelchair ergometer).............63 


\section{LISTA DE TABELAS}

TABELA 1- Resultados da Calibração Externa Estática................................45 


\section{LISTA DE ABREVIATURAS E SIGLAS}

cm - centímetro

$\mathrm{Kg}$ - kilograma

Kgf - kilograma - força

$\mathrm{Km} / \mathrm{h}$ - kilometros por hora

$\mathrm{Kpm}$ - kilometros por minuto

$\mathrm{m}-$ metro

$\mathrm{mm}$ - milímetros

$\mathrm{N}$ - Newton

$\mathrm{Nm}$ - Newton metro

$\mathrm{O}_{2}$ - oxigênio

rpm - rotações por minuto

$\mathrm{VO}_{2}$ - volume de oxigênio consumido por minuto

$\mathrm{VO}_{2}$ máx - volume máximo de oxigênio que pode ser consumido por minuto durante o exercício

W - watts 


\section{SUMÁRIO}

RESUMO

ABSTRACT

LISTA DE FIGURAS

LISTA DE TABELAS

LISTA DE ABREVIATURAS E SIGLAS

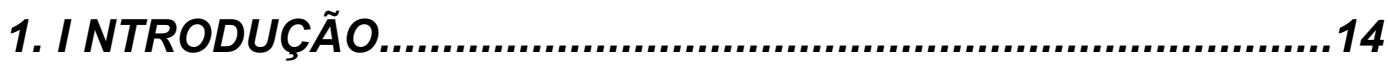

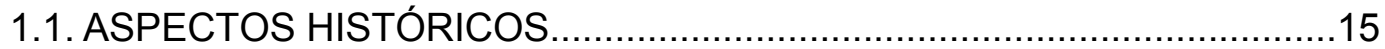

1.2. CICLO ERGÔMETRO PARA EXERCÍCIO DE MEMBROS

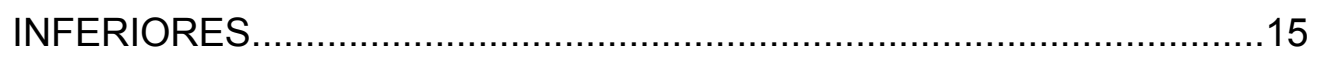

1.3. CICLO ERGÔMETRO PARA EXERCíCIO DE MEMBROS

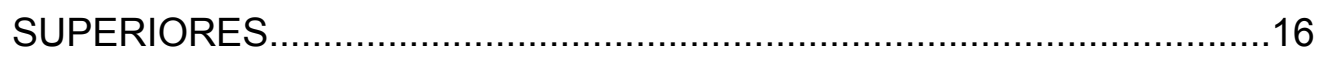

1.4. CICLO ERGÔMETRO PARA EXERCÍCIO DE MEMBROS SUPERIORES E INFERIORES.

1.4.1. Schwinn Air Dyne Ergometer .................................................19

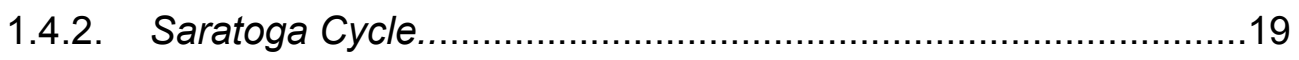

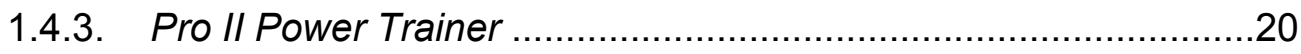

1.5. BENEFÍCIOS DO EXERCÍCIO ERGOMÉTRICO DOS MEMBROS SUPERIORES E INFERIORES. 


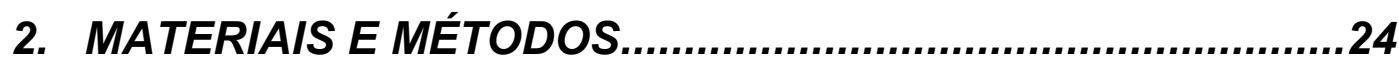

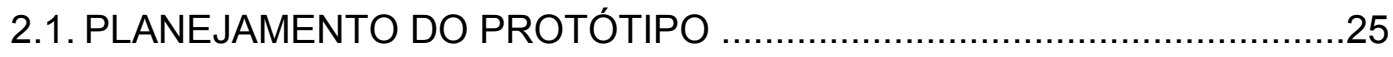

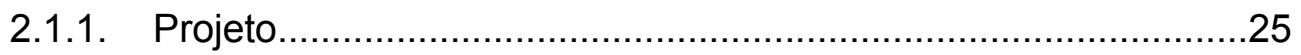

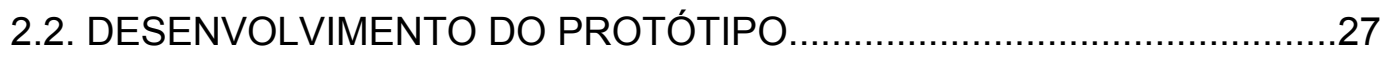

2.2.1. Base de Sustentação ..............................................................27

2.2.2. Coluna Regulável e Manípulos................................................28

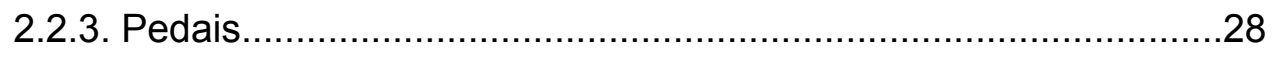

2.2.4. Sistema de Movimentação Conjunta.............................................28

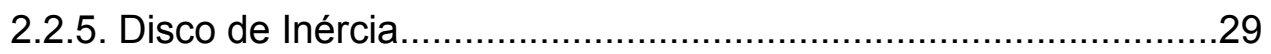

2.2.6. Sincronismo dos Movimentos entre Pedais e Manípulos..............32

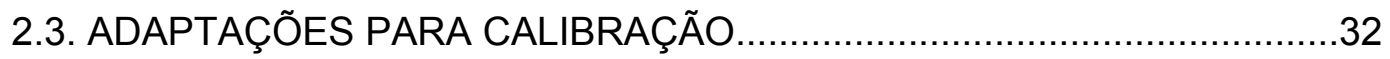

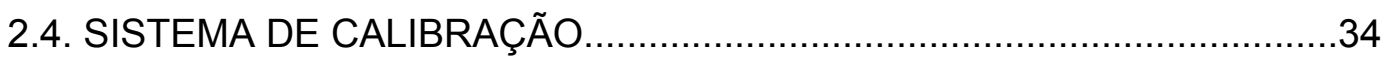

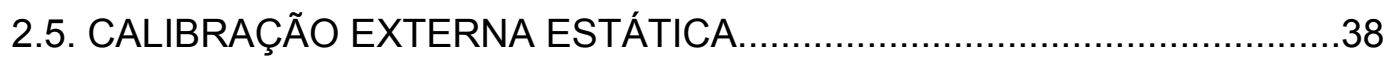

2.6. CALIBRAÇÃO ESTÁTICA DOS MANÍPULOS E PEDAIS...........................38

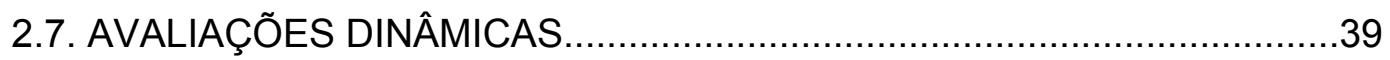

2.7.1. Teste em Pessoa Normal..........................................................39

2.7.2. Avaliação Dinâmica dos Manípulos............................................39

2.7.3. Avaliação Dinâmica dos Pedais..................................................... 40

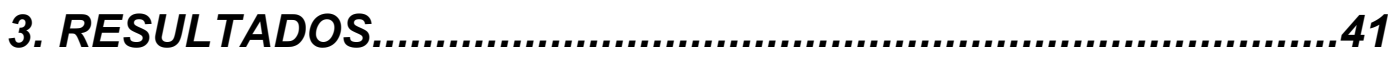

3.1.RESULTADOS DA CALIBRAÇÃO EXTERNA ESTÁTICA..........................43

3.2. CALIBRAÇÃO ESTÁTICA DOS MANÍPULOS.........................................46

3.3. CALIBRAÇÃO ESTÁTICA DOS PEDAIS.............................................. 
4. DISCUSSÃO .58

4.1.RELEVÂNCIA DO CICLO ERGÔMETRO PARA MEMBROS SUPERIORES E INFERIORES .66

5. CONCLUSÕES. 
1. INTRODUÇÃO 


\subsection{ASPECTOS HISTÓRICOS}

Inventadas no século XIX as primeiras bicicletas eram impulsionadas pelos pés do ciclista, sem pedais, embora existam registros anteriores de desenhos e escritos de Leonardo da Vinci em um museu de Madri, demonstrando precocemente o uso da transmissão por corrente. Apenas com o surgimento do velocípede em 1855 que as teorias de Leonardo da Vinci começaram a ser utilizadas (www.bikerzl.hpg.ig.com.br).

Desenvolvido inicialmente na França, por Michaux, o velocípede com a adição das manivelas e pedais marca o começo de uma linha contínua de desenvolvimento que conduz à bicicleta moderna.

Desde então o velocípede apreciou uma popularidade considerável na Europa e América do Norte, patenteado nos Estados Unidos em 1866 por Pierre Lallement, somente em 1890 houve um aumento fenomenal no número de fabricantes e usuários de bicicletas em torno do mundo.

Inicialmente inventada para servir de locomoção, passou a ser também utilizada para a prática de atividade física, tornando um importante instrumento de treinamento.

\subsection{CICLO ERGÔMETRO PARA EXERCÍCIO DE MEMBROS INFERIORES}

Acompanhando o avanço da mecânica ciclística, desenvolveu-se um modelo especial - a bicicleta estacionária - que permitia ser utilizada em ambientes internos, independente das condições climáticas ou ambientais externas. 
A bicicleta estacionária ou ciclo ergômetro tornou-se um aparato familiar encontrado na maioria das instituições onde o exercício terapêutico é prescrito, recebendo aceitação universal.

Foi sugerida como equipamento para aumentar a extensão dos movimentos do quadril, joelho e tornozelo, bem como para fortalecer os músculos e melhorar a amplitude de movimento da extremidade em geral (HOUTZ, et al., 1959; SMITH, 1939; DAWSON, 1953; BEARSY, 1947).

O ciclo ergômetro tradicional é comumente usado na execução e graduação de exercícios para muitas pesquisas com sujeitos humanos, nos laboratórios clínicos. Muitos dos estudos envolvendo este dispositivo são dirigidos a quantificar forças e suas respostas fisiológicas (HARMAN et al., 1987).

Durante décadas este equipamento foi um dos mais utilizados para estudos dos aspectos fisiológicos e biomecânicos das funções músculo esqueléticas, proporcionando o condicionamento e reabilitação da estrutura corporal debilitada

Atualmente a prática regular de atividades físicas vem sendo considerada um importante fator para o equilíbrio do balanço energético, tendo seus efeitos amplamente estudados nas diversas áreas do conhecimento. Com o exercício físico podemos avaliar o metabolismo energético do indivíduo em todos os períodos do desenvolvimento humano (infância, adolescência, senescência) até em casos específicos, como por exemplo, o ciclo reprodutivo, dislipidemias e deficiências motoras (SENE, 2003).

\subsection{CICLO ERGÔMETRO PARA EXERCíCIO DE MEMBROS SUPERIORES}

Outra etapa do desenvolvimento deste importante equipamento foi a criação do ciclo ergômetro de braço. 
O ciclo ergômetro de braço ou arm crank ergometer (Figura 1) é um equipamento que possui uma variedade de colocações, incluindo: reabilitação em clínicas (principalmente na reabilitação do ombro), laboratórios de pesquisa, centros de aptidão e condicionamento cardiovascular, ou até centros de treinamento olímpicos. Desde o ano de 1970, uma quantia considerável de pesquisas enfocando as respostas cardiovasculares para o exercício na bicicleta de braço, validou o seu uso como ferramenta para a pesquisa de aptidão cardiovascular (BRESSEL et al.,2001).

Atualmente, este modelo de equipamento para treinamento da extremidade superior está aumentando sua popularidade e utilização clínica (SCOTT et al., 1984).

O ergômetro para a parte superior do corpo pode ser usado nas fases iniciais da reabilitação, a fim de restaurar a amplitude de movimento e, nas fases subseqüentes, para a resistência muscular. A máquina inercial pode aprimorar a coordenação e a sincronia, assim como para o fortalecimento excêntrico, particularmente dos músculos que participam da desaceleração do ombro (ANDREWS et al., 1998).

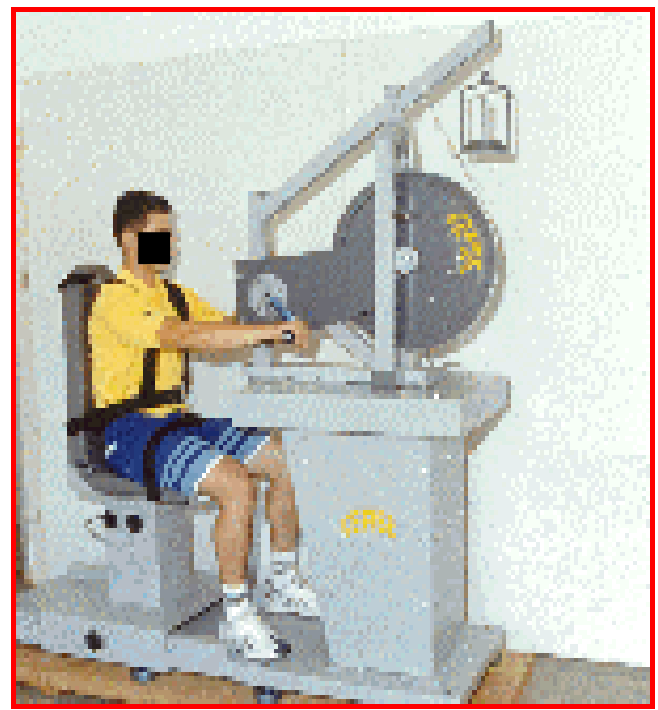

Figura 1. Ergômetro de braço (M4100).

Fonte: Disponível em: www.cefise.com.br. Acesso em 06 set. 2002. 
A realização de testes e treinamento do membro superior, como também da extremidade inferior, tem importantes implicações na reabilitação cardíaca e medicina reabilitativa. Exercícios com a extremidade superior são usualmente indicados para indivíduos que necessitem de atividades ocupacionais ou recreacionais envolvendo trabalho de braço, como também para pessoas incapazes de realizar trabalho de perna, como paraplégicos ou indivíduos com debilidades da extremidade inferior (SCOTT et al., 1984; FARDY et al.,1977).

Ergométricas com manivelas para braços são, na maioria, confiáveis e válidas para a evolução clínica e funcional de pacientes em cadeira de rodas, na performance de exercícios prescritos individualmente nos programas de treinamento de pacientes com lesão espinhal e outras deficiências físicas como hemiplegia e reabilitação cardíaca (DICARLO, 1988; NILSSON et al.,1975).

Esses programas são considerados altamente efetivos para a melhora e manutenção da atividade física de indivíduos portadores de deficiências físicas (DICARLO,1988; COWELL et al.,1986; KNUTSSON et al.,1973; NILSSON et al.,1975), assim como para redução dos riscos cardiovasculares (BRENES et al.,1986; COWELL et al.,1986; HOFFMAN, 1986).

\subsection{CICLO ERGÔMETRO PARA EXERCÍCIO DE MEMBROS SUPERIORES E INFERIORES}

Pensando nos benefícios que poderiam ser alcançados pelo exercício associado dos membros, surgiu o ciclo ergômetro para membros superiores e inferiores. Dentre eles estão o Schwinn Air Dyne Ergometer, Saratoga cycle e Pro II power trainer. 


\subsubsection{Schwinn Air Dyne Ergometer}

A construção deste equipamento possibilitou, com o trabalho combinado de braços e pernas, o estudo das respostas cardiovasculares agudas e crônicas para populações de amputados, melhorando a função de propulsão de cadeira de rodas e deambulação com próteses (BOSTOM et al., 1987).

\subsubsection{Saratoga Cycle}

O original Saratoga cycle (Figura 2) foi desenvolvido em 1987 por um quadriplégico (C5/6) e sua esposa, terapeuta ocupacional, para suprir suas próprias necessidades. Saratoga cycle é um tipo de ergômetro que atende a maioria da população, oferece exercício para membros superiores ou inferiores isoladamente, ou para ambos de modo sincronizado (www.easypivot.com/models/spiritfeatureschart.htm).

O Saratoga cycle necessita do assento em cadeira ou cadeira de rodas e o posicionamento dos pedais estão situados à frente do paciente em um eixo único.

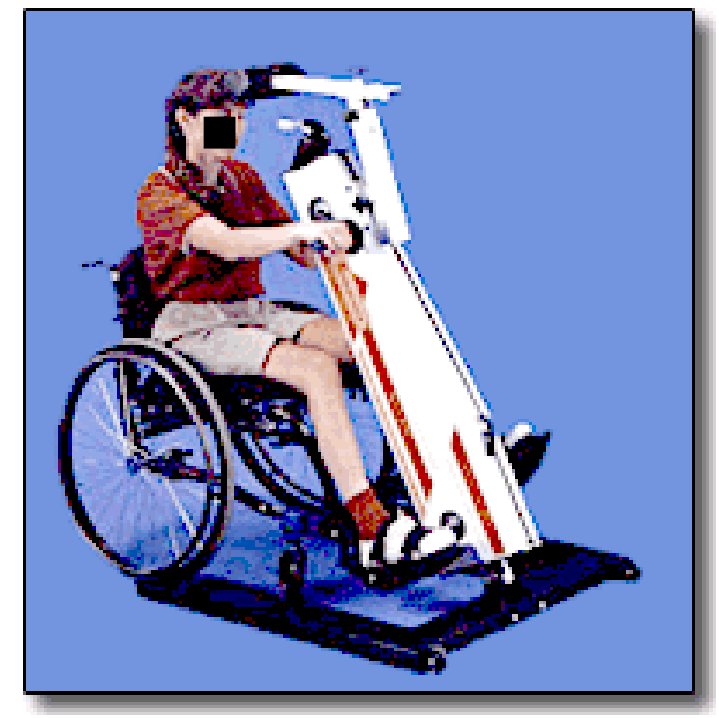

Figura 2. "Saratoga Spirit 690", bicicleta para braços e pernas.

Fonte: Disponível em:www.easypivot.com/saratoga/models/spiritfeatureschart.htm. Acesso em: 26 nov. 2003. 


\subsubsection{Pro II Power Trainer}

O ciclo ergômetro Pro /l Power Trainer (Figura 3), também oferece as mesmas condições de exercício para membros superiores e inferiores, possui assento com encosto, porém o posicionamento dos pedais está à frente do paciente e não abaixo.

Loudon e colaboradores, no ano de 1998, propuseram desenvolver e validar um teste de exercício submáximo usando o Pro // Power Trainer, e desenvolveram após os testes, uma equação de regressão linear para predizer o pico de $\mathrm{VO}_{2}$ dos dados submáximos usando a taxa cardíaca e a produção de força aos sexto e nono minutos do teste submáximo.

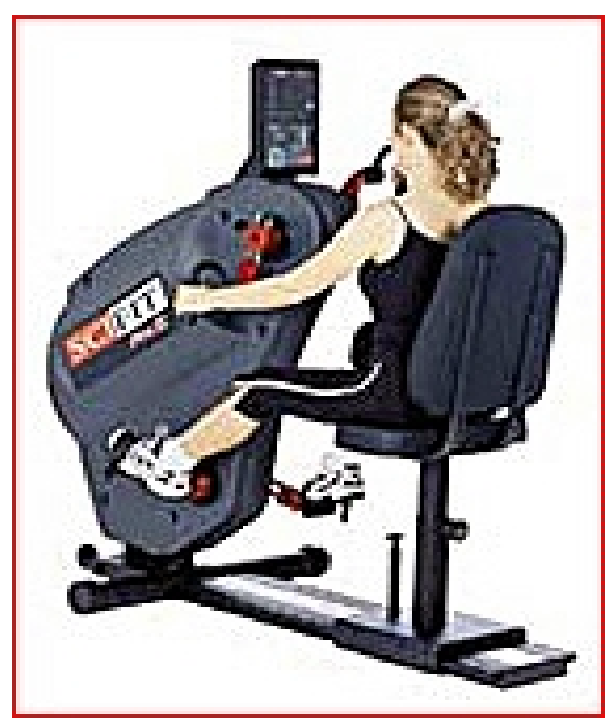

Figura 3. "Pro II power trainer" para membros superiores e inferiores. Fonte: Disponível em: www.noboundaries.tv/pro2.htm. Acesso em: 26 nov. 2003. 
Introdução 21

\subsection{BENEFÍCIOS DO EXERCÍCIO ERGOMÉTRICO DOS MEMBROS SUPERIORES E INFERIORES}

Indivíduos com paraplegia ou tetraplegia, apresentam uma redução na capacidade física de trabalho (POLLOCK et al.,1974; GASS et al., 1979), onde até mesmo atividades limitadas resultam em fadiga. A paraplegia conduz a um processo degenerativo, resultando na diminuição da massa corporal, reduzindo a capacidade aeróbica, levando a condições osteoporóticas e disfunções renais (COWELL et al., 1986).

Prevenir a fadiga desses indivíduos pode garantir uma boa participação no trabalho e nas atividades recreativas (DICARLO,1986). Indivíduos que participam de treinamento a altos níveis de resistência, tendem a ter uma baixa prevalência de mortalidade e doenças coronárias (PAFFENBARGER et al., 1975), menor risco de hipertensão (RESSL et al., 1977), obesidade (OSCAL, 1973) e ataque cardíaco (PAFFENBARGER R. S. et al., 1970).

Atualmente o ciclo ergômetro de braço é um método usual para avaliação da aptidão e capacidade de trabalho de paraplégicos. Outras investigações comparam a eficiência de vários outros métodos de execução de exercício, procurando delinear o melhor método para indivíduos com patologias de membros inferiores.

Em 1979, Hjeltnes e Vokac realizaram cinco estudos voltados à reabilitação de paraplégicos, com monitoramento da taxa cardíaca durante 48 horas em ambiente domiciliar. Os autores relataram que, da mesma maneira que é visto em pessoas saudáveis, as atividades cotidianas desses sujeitos não extraíram índices de taxas cardíacas dentro da extensão apropriada para se obter um treinamento efetivo.

Em uma pessoa saudável, os exercícios de treinamento devem ser executados a $60-70 \%$ da capacidade aeróbica máxima $\left(\mathrm{VO}_{2}\right.$ máx), porém nos paraplégicos, isso pode ser mostrado nas cargas de trabalho equivalentes à 
$50-60 \%$ da taxa cardíaca de reserva que contribui para a manutenção da aptidão circulatória (MARINCEK e VALENCIC,1978).

Baseado nos resultados deste e de vários outros estudos, conclui-se que sem um programa de treinamento, paraplégicos, da mesma maneira que quaisquer outras pessoas, não podem manter ou melhorar sua aptidão cardiovascular (COWELL et al.,1986).

Glaser e colaboradores, 1981, constataram que a energia despendida para locomoção na cadeira de rodas a uma velocidade de caminhada normal de $4.0 \mathrm{Km} / \mathrm{h}$ é similar ou maior que para a caminhada de um indivíduo saudável e que o stress cardiovascular é maior durante a operação na cadeira de rodas devido à menor porcentagem de massa muscular ativa, comparados à larga massa muscular das pernas.

Petrofsky e colaboradores, 1983, estabeleceram um meio para treinar passivamente os membros inferiores de paraplégicos e quadriplégicos, subseqüente ao desenvolvimento de um triciclo ao ar livre, conduzido por indivíduos saudáveis. O treino das pernas permite aos paraplégicos, por via de controle computadorizado, mover suas pernas e contrair a musculatura atrofiada, conseqüentemente restabelecer o diâmetro ósseo e alongamento. A desvantagem deste aparato é que não possibilita a variação de resistência.

O desenvolvimento deste triciclo oferece meios de aumentar a mobilidade de indivíduos com lesão medular e, ao mesmo tempo, condicionar a musculatura paralisada, aumentando a aptidão cardiovascular.

Pimental e colaboradores, 1984, realizaram um estudo comparativo entre as respostas fisiológicas de 60 minutos contínuos de exercício no ciclo ergômetro de braço e bicicleta ergométrica a intensidades de exercício relativas e absolutas. Demonstrou-se que o exercício na bicicleta de braço pode ser sustentado a $60 \%$ do pico de produção de $0_{2}$ por 60 minutos e que este exercício obteve respostas da análise sanguínea dos volumes de plasma e trocas de lactato similares às observadas durante exercício na bicicleta ergométrica durante as mesmas intensidades relativas. 
As respostas da taxa cardíaca são mais baixas para o exercício no ciclo ergômetro de braço que para a bicicleta ergométrica.

No exercício com ergômetro de braços ou pernas, tensões de várias intensidades e direções são aplicadas, e todos esses esforços fazem parte do desenvolvimento do corpo humano, uma vez que evitam atrofias musculares e ósseas, e promovem sua manutenção (MARINHEIRO, 2003).

Em estudos utilizando a bicicleta de braço como equipamento de exercício resistivo, Clausen e colaboradores, 1973 e DiCarlo e colaboradores, 1983, demonstraram que este exercício resulta no aumento do consumo máximo de $\mathrm{O}_{2}\left(\mathrm{VO}_{2}\right.$ máx), induz a bradicardia (diminui a taxa cardíaca no final no trabalho de carga submáxima) e aumenta a capacidade de trabalho físico. Essas adaptações podem resultar em melhorias significantes na resistência funcional, assim reduzindo a fadiga durante a propulsão da cadeira de rodas e outras atividades de vida diária (DiCARLO, 1986).

Analisando o importante papel do ergômetro de braço e da bicicleta ergométrica na medicina de reabilitação, e considerando que a união desses dois mecanismos representa um avanço importante para o tratamento de várias patologias, o objetivo deste trabalho foi desenvolver um equipamento global com recursos nacionais e de baixo custo. 
2. MATERIAIS E MÉTODOS 
O trabalho desenvolvido foi dividido em três etapas, a primeira destinouse ao planejamento, desenho e confecção do protótipo, executado na cidade de Santa Fé do Sul, São Paulo. Um estudo das variações antropométricas foi utilizado para auxiliar no dimensionamento do aparelho.

Após a definição do modelo e padronização das medidas, a estrutura do equipamento foi construída.

$\mathrm{Na}$ segunda etapa do projeto, com apoio dos Laboratórios de Aeronaves, Metrologia e Laboratório de Máquinas e Ferramentas, todos da Universidade de São Paulo, obteve-se a versão final do aparelho, com aperfeiçoamento dos mecanismos de resistência e adaptações para calibração.

A terceira e última etapa destinou-se às calibrações estáticas e avaliações dinâmicas do equipamento.

\subsection{PLANEJAMENTO DO PROTÓTIPO}

\subsubsection{Projeto}

Primeiramente, realizou-se um desenho esquemático, com adaptações à bicicleta ergométrica convencional, que possibilitasse o movimento rotacional dos membros superiores e inferiores, de maneira conjunta e sincrônica.

O desenho (Figura4), permitiu o prévio estudo dos materiais a serem utilizados na confecção e adaptação do equipamento, onde se priorizou a utilização de componentes disponíveis comercialmente. 
O dimensionamento dos componentes do protótipo procurou dar opções de regulagem à altura do selim e à coluna de fixação dos manípulos, devido às variações antropométricas das populações.

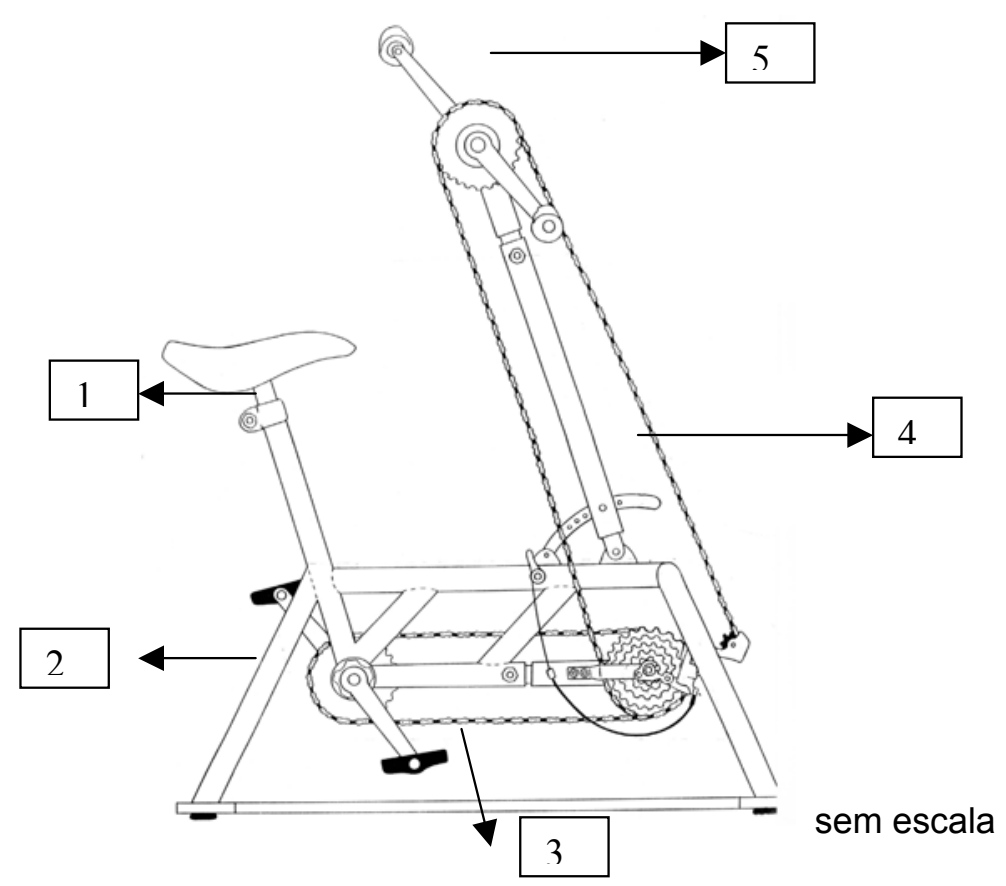

Figura 4- Desenho do protótipo inicial: 1) banco regulável; 2) base de apoio; 3) pedais; 4) coluna regulável; 5) manípulos

As principais características que o primeiro protótipo definiu foram:

- Estabelecimento de diretrizes;

- Ajuste e acoplamento das engrenagens, permitindo o movimento rotativo simultâneo dos membros superiores e inferiores. 


\subsection{DESENVOLVIMENTO DO PROTÓTIPO}

Os componentes do protótipo foram confeccionados em uma serralharia no município de Santa Fé do Sul, SP.

\subsubsection{Base de Sustentação}

A estrutura do equipamento foi desenvolvida em "AISI 1020", formando uma base de apoio equilibrada na forma de um quadro onde se eleva frontalmente uma coluna regulável de sustentação dos manípulos, posteriormente um suporte para o banco, e inferiormente um apoio para os pedais.

A FIGURA 5 apresenta o protótipo do equipamento.

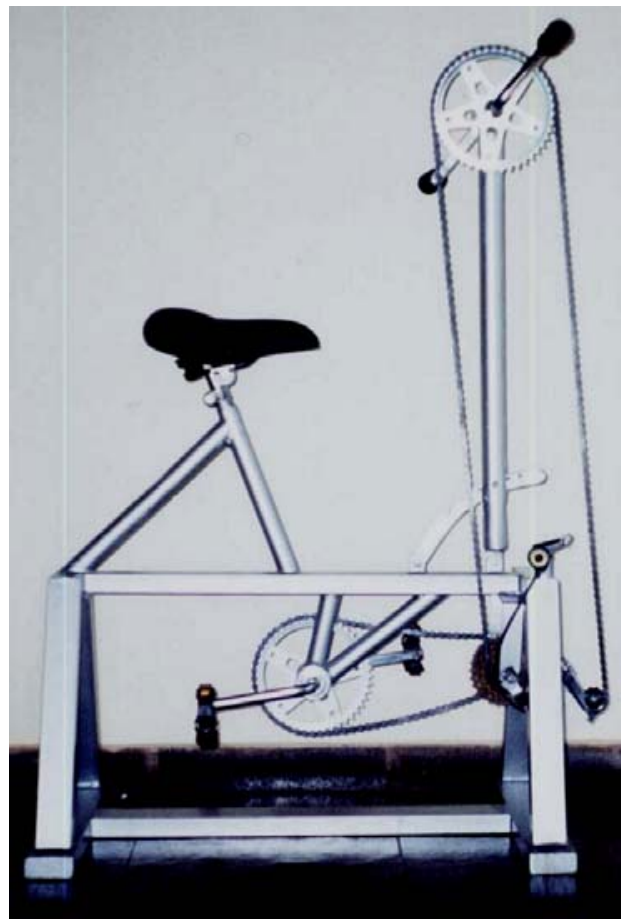

Figura 5. Bicicleta em vista lateral. 


\subsubsection{Coluna Regulável e Manípulos}

A coluna regulável sustenta em sua extremidade superior um cubo com pés de vela adaptados com luvas para manipulação, conectado em sua lateral direita uma coroa para receber a corrente.

\subsubsection{Pedais}

$\mathrm{Na}$ extremidade inferior da base de apoio da bicicleta, foram colocados pés de vela que sustentam pedais intermediados do lado esquerdo por uma coroa por onde passa a corrente.

\subsubsection{Sistema de Movimentação Conjunta}

Para associar os movimentos de pedal e manípulo, foi fixado à base de apoio um cubo de alumínio, com rosca em ambos os lados, onde em uma extremidade foi acoplada uma catraca de marcha conectada aos manípulos, que com o ajuste de um câmbio, possibilita a alternância entre as coroas de maior e menor diâmetro para o movimento rotativo dos membros superiores.

A utilização da catraca de marcha e seu intercâmbio entre coroas de maior e menor esforço, permite que as mãos conduzam os pés de forma mais leve, podendo ser útil para o exercício de indivíduos com membros inferiores paralisados.

$\mathrm{Na}$ outra extremidade do cubo apóia-se uma roda livre, ligada aos pedais. 


\subsubsection{Disco de Inércia}

Para fornecer a resistência necessária ao movimento do equipamento foi adquirido um disco de inércia de $290 \mathrm{~mm}$ de diâmetro (Figura 6), feito de ferro fundido, muito usado em bicicletas ergométricas. Este, possui um orifício central por onde foi inserido um eixo de ferro, para fixação ao garfo.

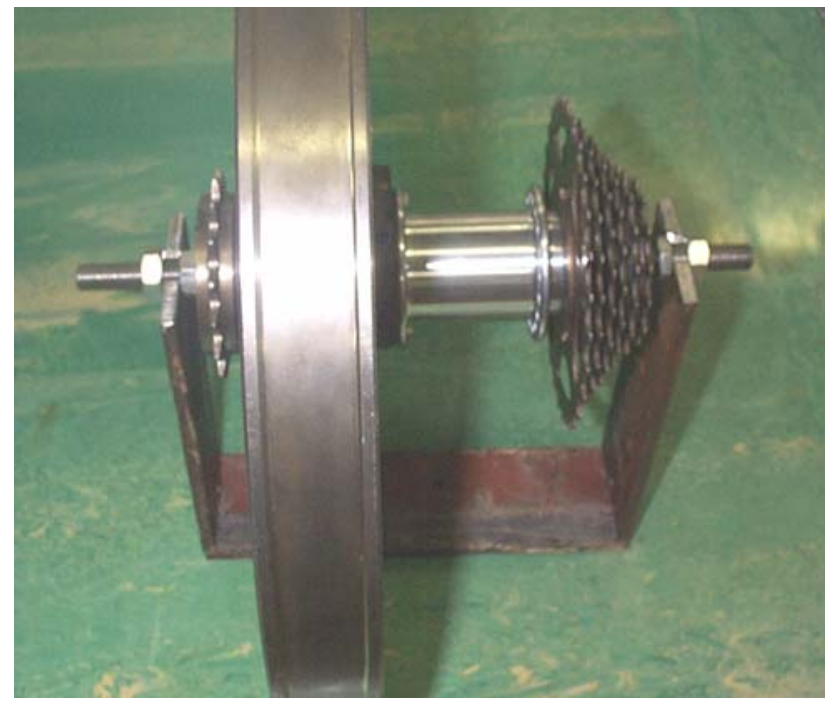

Figura 6. Garfo de sustentação do disco de inércia e torquímetro.

Ao disco de inércia foi acoplada uma fita de couro, ajustada manualmente por um dispositivo de graduação de resistência (Figura 7). 


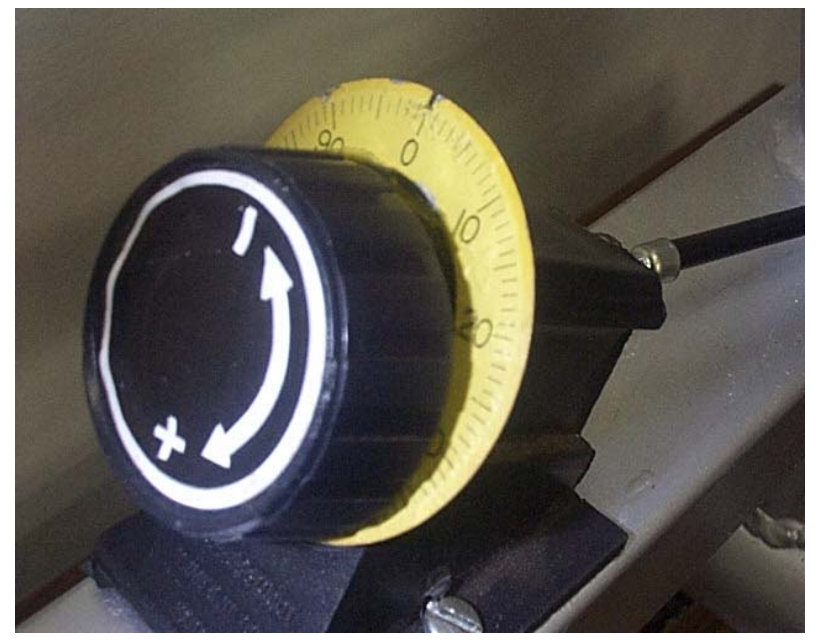

Figura 7. Dispositivo de graduação de resistência.

As rodas livres foram acopladas uma de cada lado do disco, preservando a idéia inicial.

Nas FIGURAS 8 e 9, a seguir, é visualizado o disco de inércia montado na bicicleta estacionária adaptada para membros superiores e inferiores. 


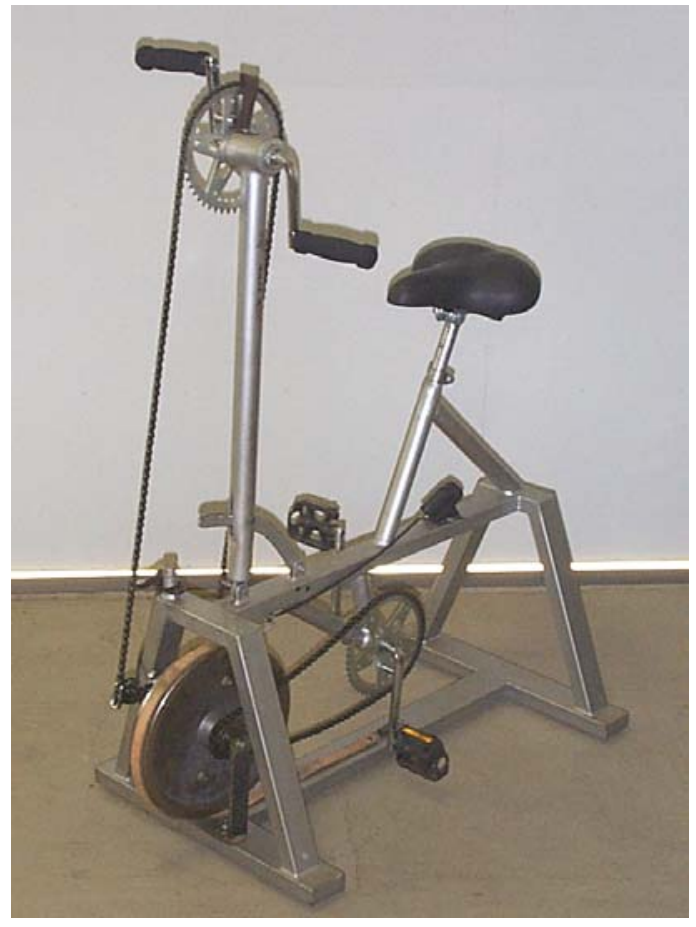

Figura 8. Bicicleta em vista fronto lateral.

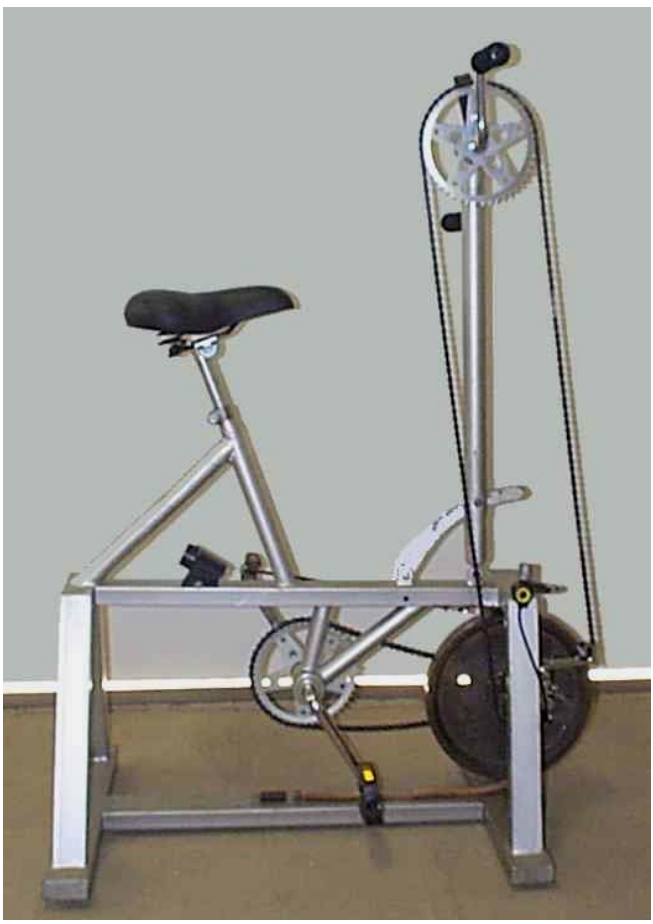

Figura 9. Bicicleta em vista lateral.

Para adequar a resistência exercida pelo disco, este foi substituído por outro menor, com diâmetro de $254 \mathrm{~mm}$, onde se obteve uma boa graduação verificada posteriormente durante a calibração. 


\subsubsection{Sincronismo dos Movimentos entre Pedais e Manípulos}

Observou-se que os movimentos rotativos dos membros superiores eram mais rápidos comparados com os membros inferiores. Isso se dá pela diferença entre o tamanho das coroas que interligam os sistemas. Realizou-se então, a substituição das coroas dos manípulos e da roda livre dos pedais por coroas menores, todas do mesmo diâmetro, para sincronizar os movimentos.

Somente nos manípulos utilizou-se duas coroas opcionais (Figura 10), a maior de 131,65 $\mathrm{mm}$ e a menor de $89 \mathrm{~mm}$, buscando melhor ajuste de sincronização (ajuste fino).

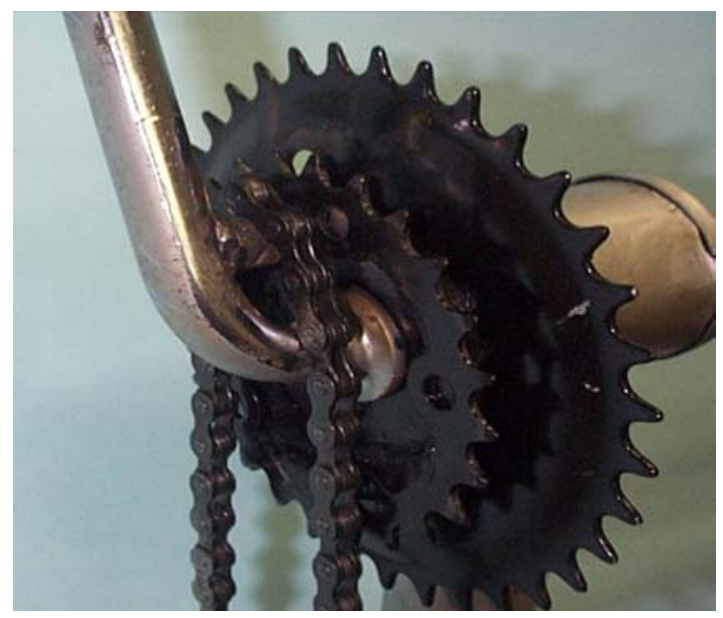

Figura 10. Coroas dos manípulos.

\subsection{ADAPTAÇÕES PARA CALIBRAÇÃO}

Para ajustar os equipamentos de calibração ao sistema de manípulos, foi utilizado um cubo de alumínio de 49,14 mm de comprimento, com diâmetro interno e externo de $32,18 \mathrm{~mm}$ e $36,11 \mathrm{~mm}$, respectivamente, previamente calculado para resistir à torção durante os testes. 
Às extremidades do cubo de alumínio foram acoplados o disco de inércia e o sistema de coroas de marcha (Figura 11).

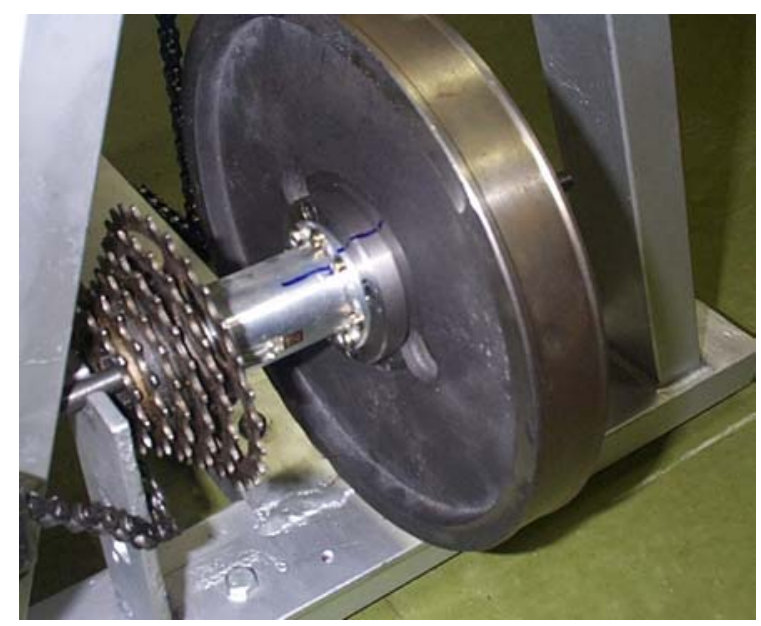

Figura 11. Fixações do cubo e da catraca de marcha.

Para o acoplamento de um torquímetro ao sistema, foi necessário deslocar lateralmente a coluna regulável do equipamento em 42,70 mm. 
A lateralização da coluna regulável (Figura 12) foi realizada somente para fins de calibração.

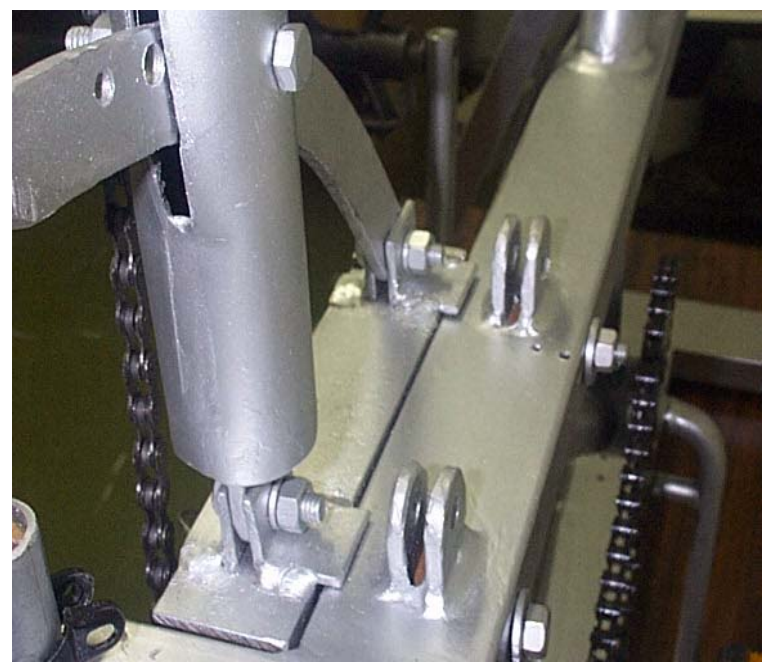

Figura 12. Lateralização da coluna regulável.

\subsection{SISTEMA DE CALIBRAÇÃO}

Foi utilizado um sistema para medição de torque em eixos rotativos por meio de telemetria (Hottinger Baldwin Messtechnik®). O sistema Modular BLM serve para captar, mensurar e transmitir valores. Habilitam o uso de strain gauges aplicados a componentes de máquinas que executam movimento de rotação ou translação. 
As FIGURAS 13 e 14 exemplificam a montagem do sistema BLM utilizado na calibração.

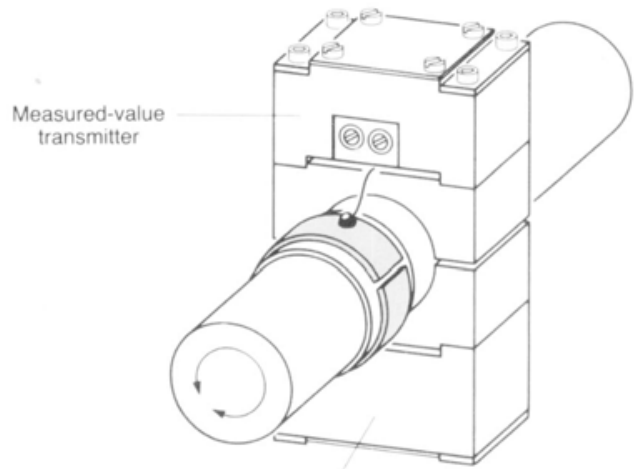

Battery box

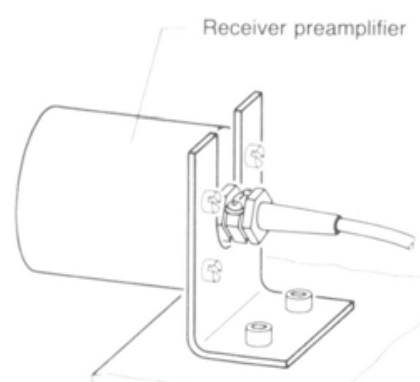

Figura 13. Medidor de valores transmitidos com bateria e receptor amplificado. Fonte: Adaptado de: Hottinger Baldwin Messtechnik/ 1987.
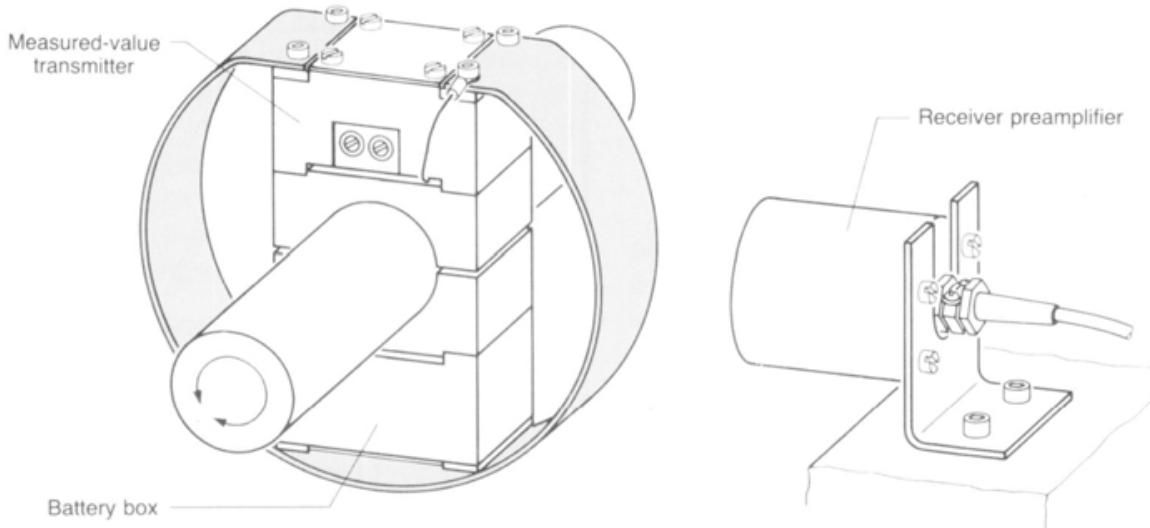

Figuras 14. Medidor de valores transmitidos com acoplamento de uma antena. Fonte: Adaptado de: Hottinger Baldwin Messtechnik/ 1987. 
O sistema de transmissão inclui quatro módulos separados que podem ser selecionados de acordo com sua aplicação:

- Medidor de valores transmitidos MT 2555A e Bateria Box BK 2801 A;

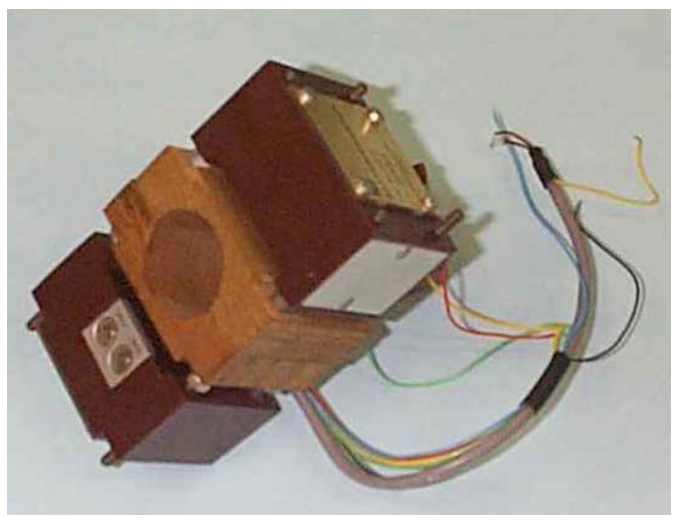

Figura 15. Medidor de valores com suporte para bateria.

- Receptor amplificado EV 2510 A;

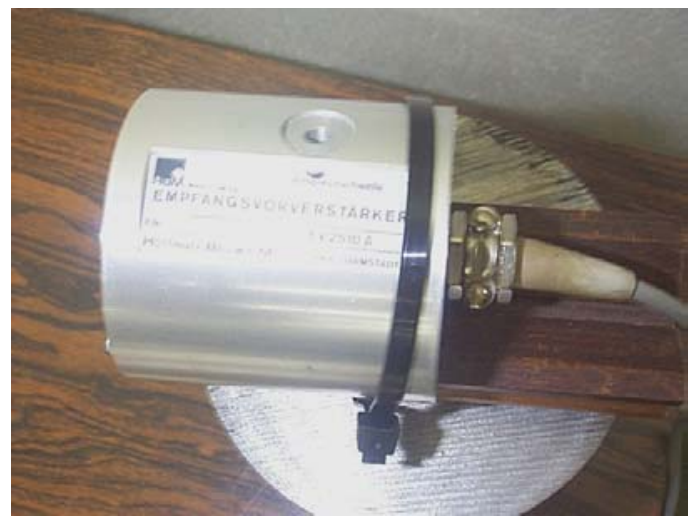

Figura 16. Receptor amplificado. 
- Transmissor rotativo DV 2802 e ponte de telemetria.

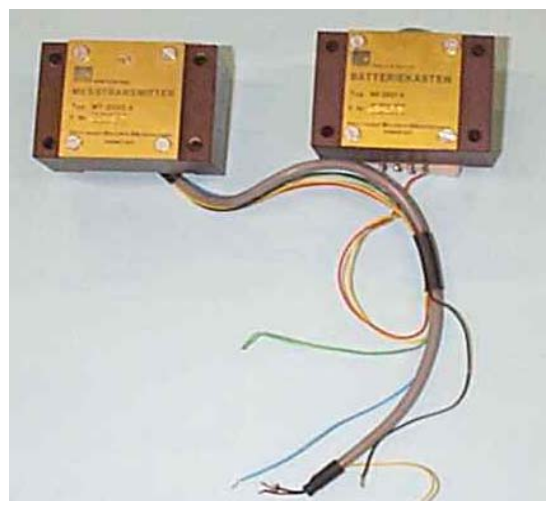

Figura 17. Transmissor rotativo.

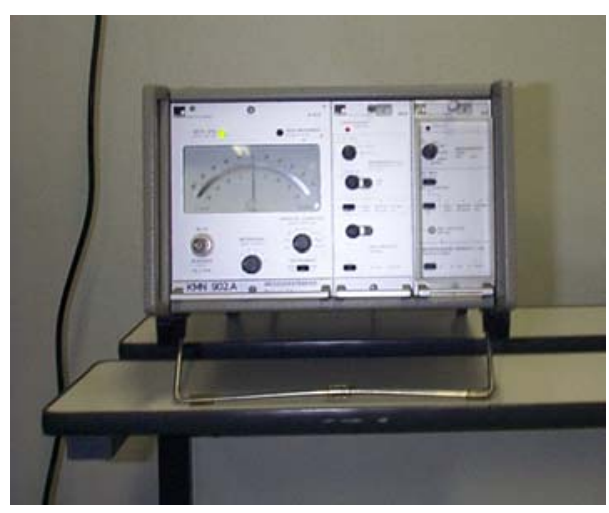

Figura 18. Ponte de telemetria.

No cubo de alumínio foi feita a colagem dos extensômetros (Figura 19), montados em ponte completa. Este sistema funcionou como um torquímetro para a calibração.

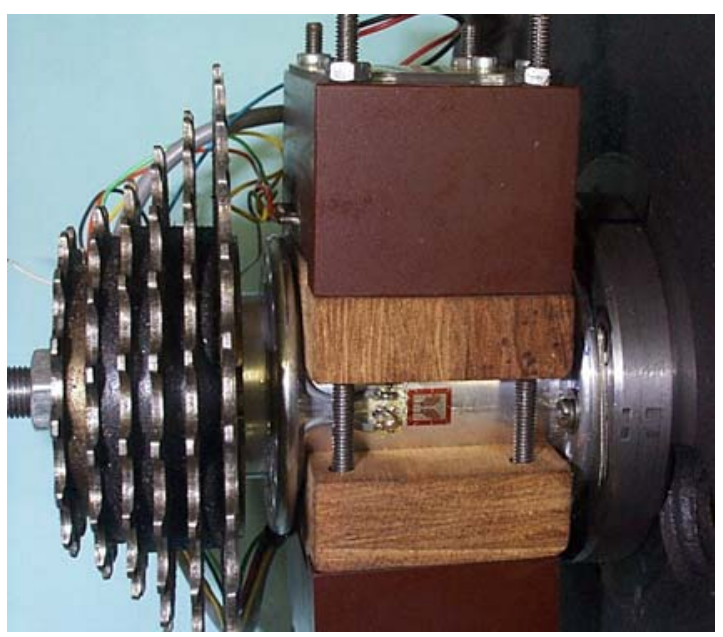

Figura 19. Extensômetros colados no cubo. 


\subsection{CALIBRAÇÃO EXTERNA ESTÁTICA}

A calibração externa estática (Figura 20) foi realizada com o disco de inércia fixo a uma mesa de ferro por um garfo, dando suporte ao torquímetro.

Utilizou-se um braço de alavanca de $147 \mathrm{~mm}$, no qual adicionavam-se pastilhas de 0.5 e $1 \mathrm{~kg}$.

A coleta de dados foi registrada pela ponte de telemetria a cada adição de peso.

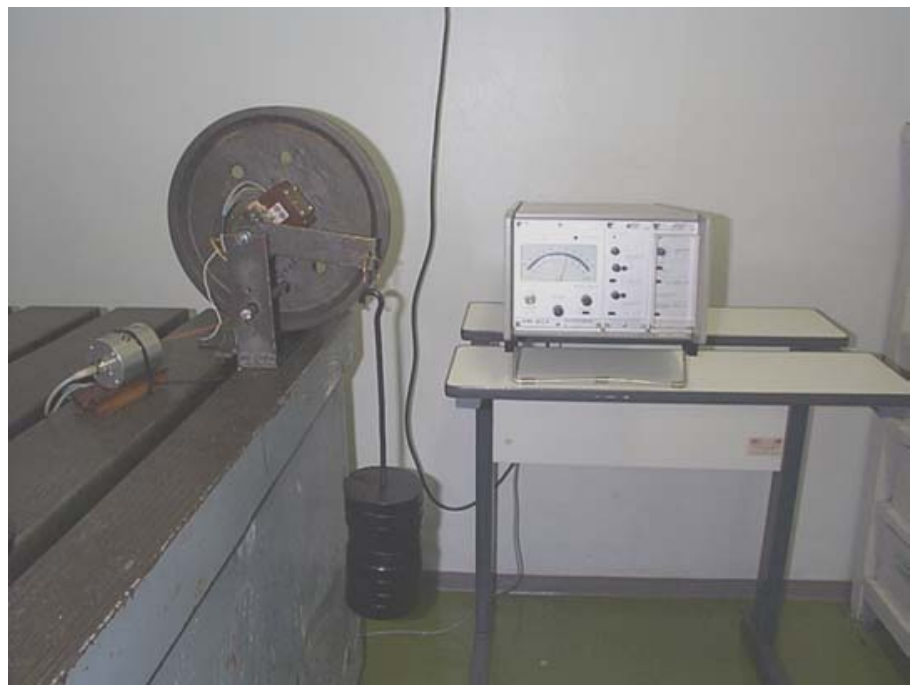

Figura 20. Calibração externa estática.

\subsection{CALIBRAÇÃO ESTÁTICA DOS MANÍPULOS E PEDAIS}

A calibração estática dos manípulos e pedais foi realizada utilizando os mesmos pesos da calibração anterior, colocados no suporte de ferro, preso aos pedais que permaneceram na posição de 90 graus. 
Os dados foram visualizados e registrados a cada adição de peso através da ponte de telemetria.

\subsection{AVALIAÇÕES DINÂMICAS}

\subsubsection{Teste em Pessoa Normal}

As calibrações dinâmicas do equipamento foram realizadas utilizando um indivíduo normal, saudável.

\subsubsection{Avaliação Dinâmica dos Manípulos}

Após a montagem do torquímetro, foi realizada a avaliação dinâmica dos manípulos.

O número de voltas do dispositivo de aperto da corrente de couro foi dimensionado em 6 ciclos, partindo do ponto $0,1,2$,3, 4, 5 .

Todas as 6 rodas livres foram avaliadas, sendo observados os valores registrados na ponte de telemetria a cada ciclo de carga, verificados durante o exercício dinâmico. 


\subsubsection{Avaliação Dinâmica dos Pedais}

Para realizar a avaliação dinâmica dos pedais foi preciso inverter a posição do torquímetro, ou seja, posicioná-lo do outro lado do disco de inércia, para registro do torque obtido nos pedais.

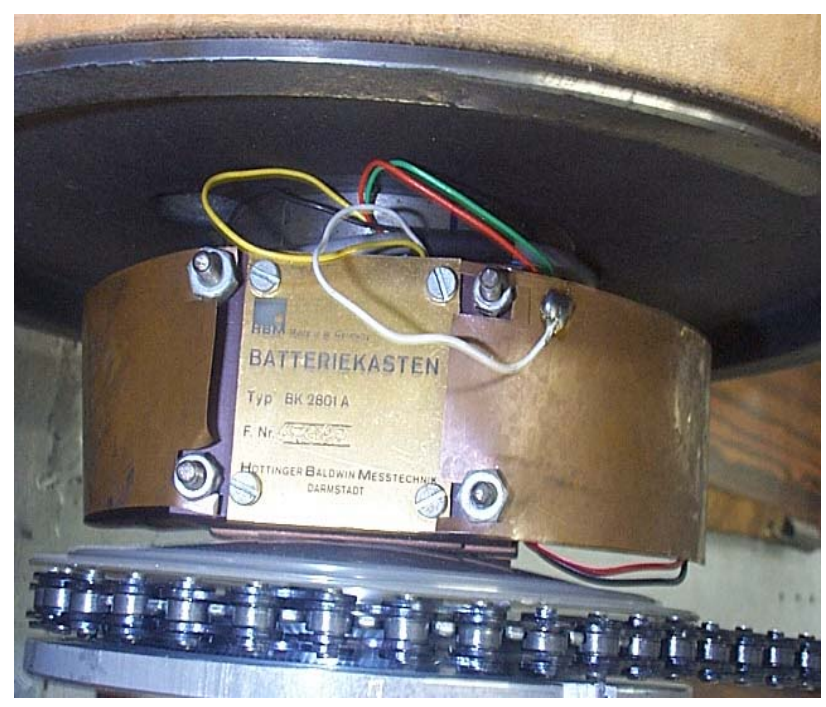

Figura 21. Inversão do torquímetro.

Esta avaliação foi feita durante os seis ciclos pré-determinados, partindo do ponto $0,1,2,3,4,5$. Os valores foram registrados na ponte de telemetria durante o exercício dinâmico. 


\section{RESULTADOS}


Os resultados foram obtidos com a versão final do protótipo do ciclo ergômetro sincronizado para membros superiores e inferiores. Os resultados referem-se aos seguintes parâmetros: 1) calibração externa estática com torquímetro; 2) calibração estática dos manípulos; 3) calibração estática dos pedais; 4) avaliação dinâmica dos manípulos e 5) avaliação dinâmica dos pedais.

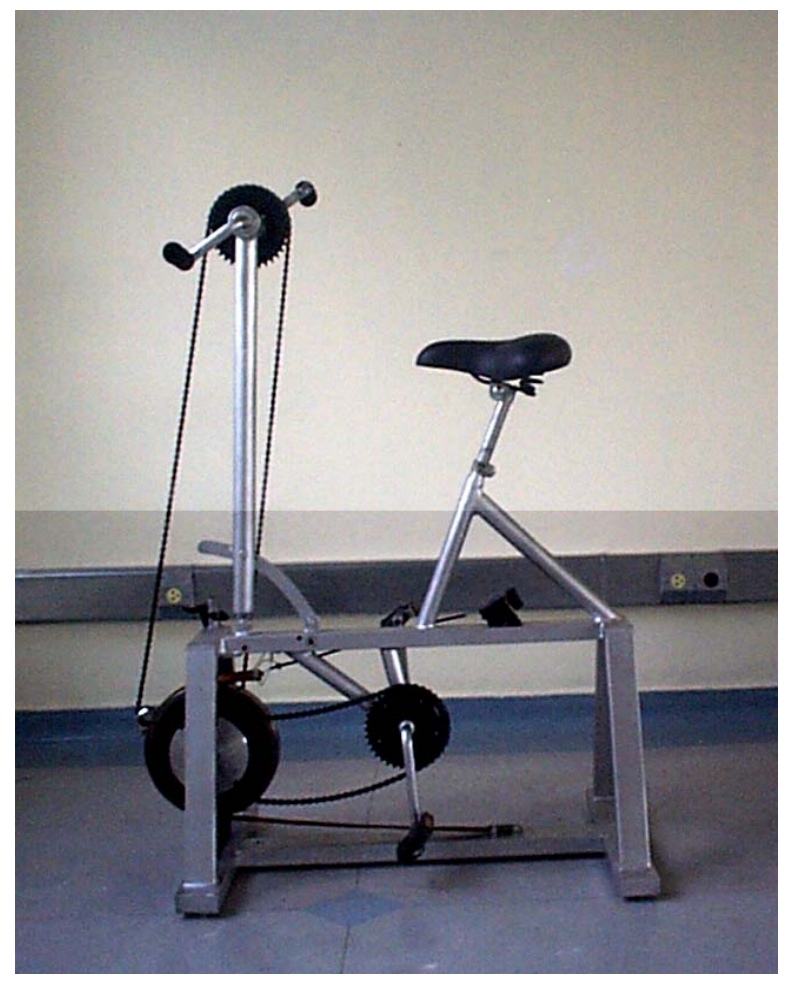

Figura 22. Versão final do ciclo ergômetro em vista lateral. 


\subsection{RESULTADOS DA CALIBRAÇÃO EXTERNA ESTÁTICA}

O gráfico abaixo apresenta a curva de calibração obtida através da adição de pesos em um braço de alavanca de $147 \mathrm{~mm}$ de comprimento, com os valores visualizados na ponte de telemetria. $O$ teste foi repetido 3 vezes, para comparar a repetibilidade dos resultados.

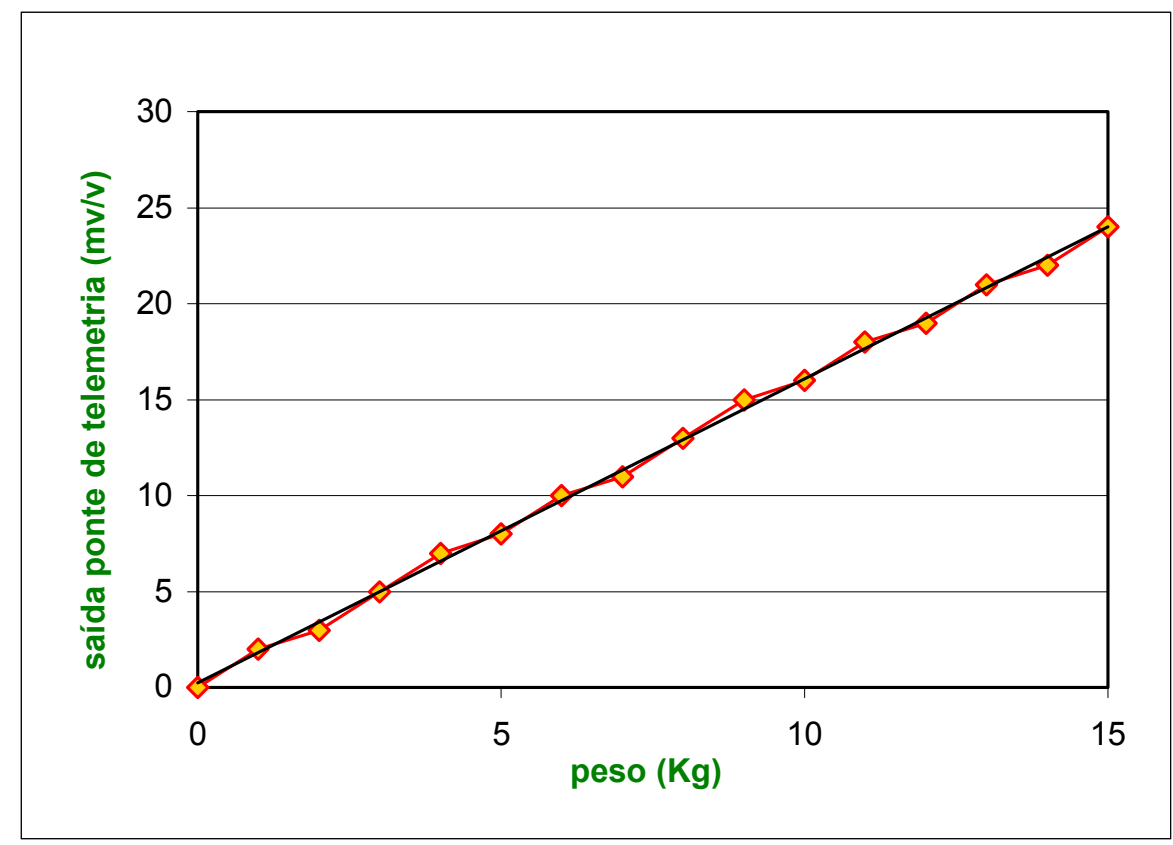

Figura 23. Calibração externa estática. 
A figura abaixo relaciona o torque e a massa utilizada na calibração externa estática.

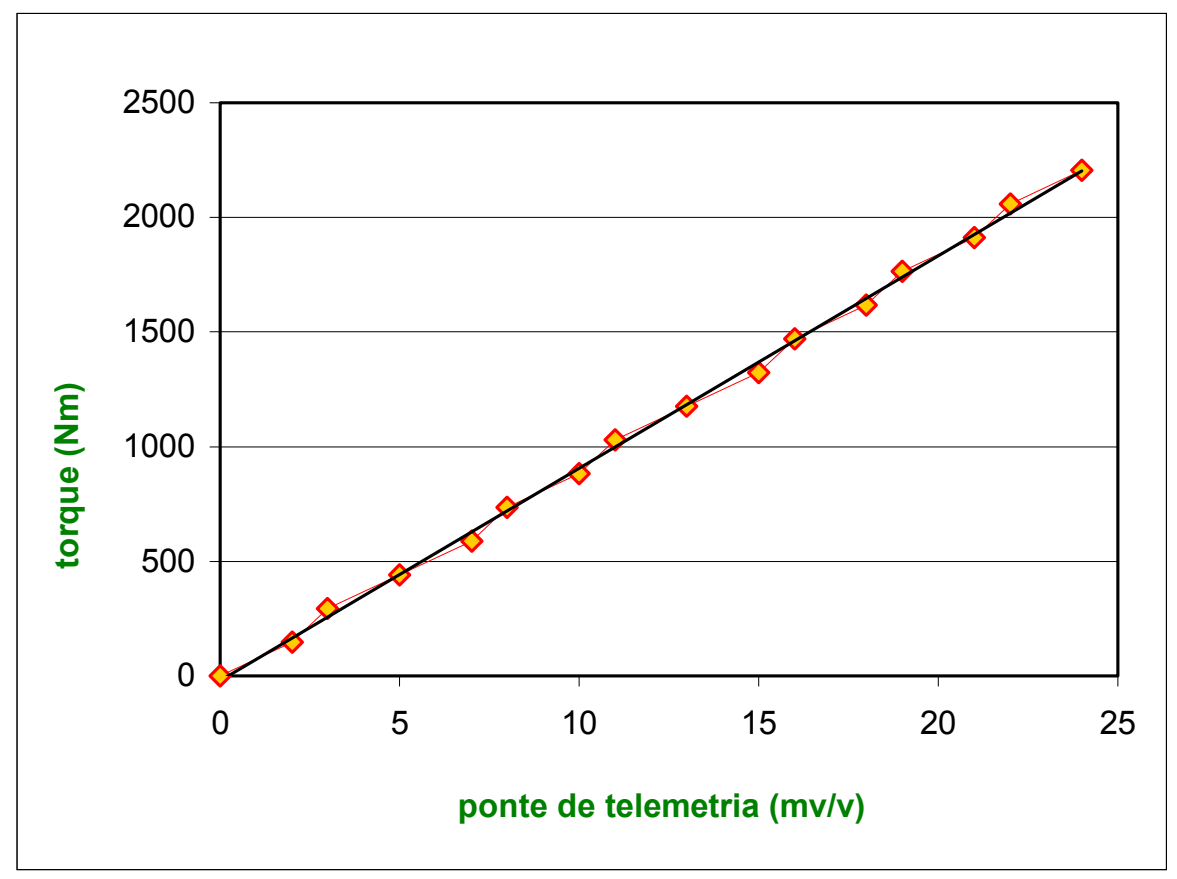

Figura 24. Apresenta o torque da calibração externa estática. 
A TABELA 1 abaixo mostra a calibração do sistema a partir de massas conhecidas.

\begin{tabular}{|c|c|c|}
\hline Massa (Kg) & Telemetria (Mv/v) & Torque (Nm) \\
\hline 0 & 0 & 0 \\
\hline 1 & 2 & 147 \\
\hline 2 & 3 & 294 \\
\hline 3 & 5 & 441 \\
\hline 4 & 7 & 588 \\
\hline 5 & 8 & 735 \\
\hline 6 & 10 & 882 \\
\hline 7 & 11 & 1029 \\
\hline 8 & 13 & 1176 \\
\hline 9 & 15 & 1323 \\
\hline 10 & 16 & 1470 \\
\hline 11 & 18 & 1617 \\
\hline 12 & 19 & 1764 \\
\hline 13 & 21 & 1911 \\
\hline 14 & 22 & 2058 \\
\hline 15 & 24 & 2205 \\
\hline
\end{tabular}

Tabela 1. Resultados da calibração externa estática. 


\subsection{CALIBRAÇÃO ESTÁTICA DOS MANÍPULOS}

Esta calibração foi realizada com os manípulos na posição de 90 graus, sustentando um suporte de ferro para adição das pastilhas de 0,5 e $1 \mathrm{Kg}$.

As pastilhas eram adicionadas individualmente até que o manípulo mantido inicialmente na posição de 90 graus começasse a esboçar movimento. Esta calibração foi efetuada para os 6 ciclos de carga determinados, como também para as seis rodas livres.

As figuras seguintes apresentam os resultados da calibração estática dos manípulos em todas as seis rodas livres as quais compõem o sistema, iniciando com a roda maior e, a seguir, com as rodas gradativamente menores.

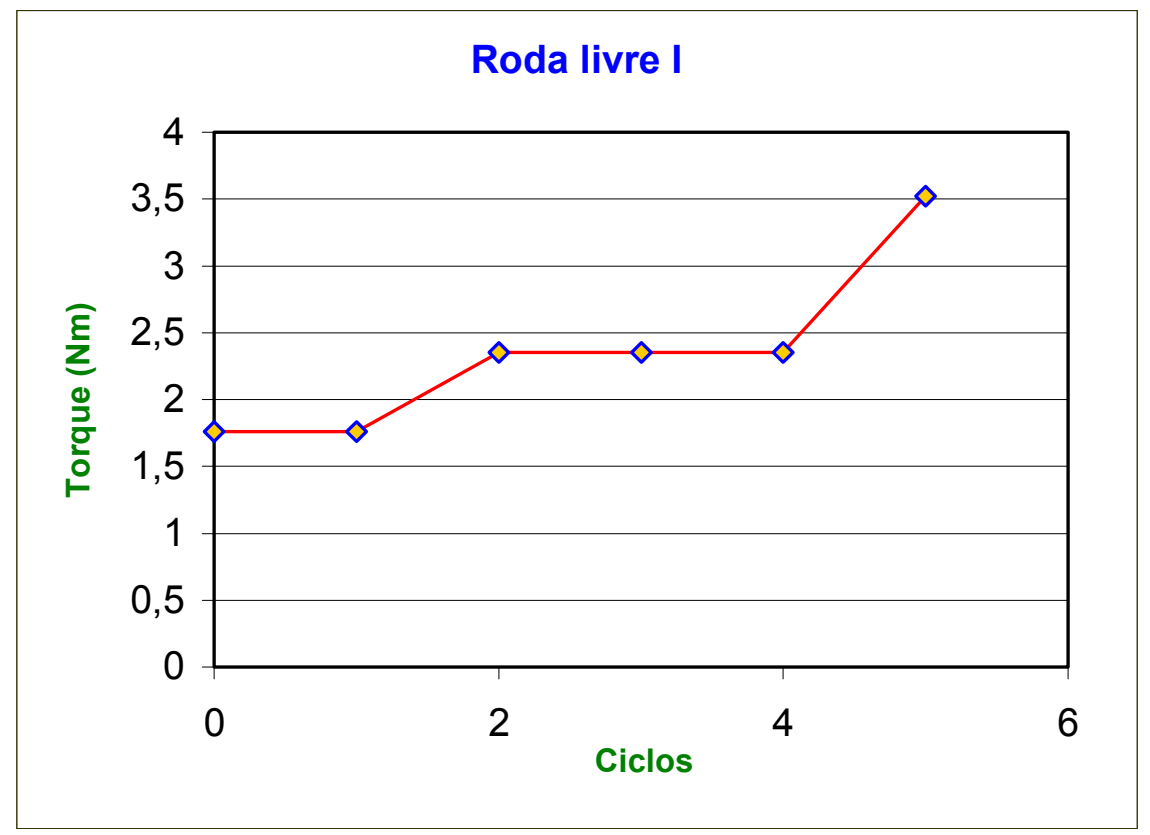

Figura 25. Torque gerado na primeira roda livre (maior). 


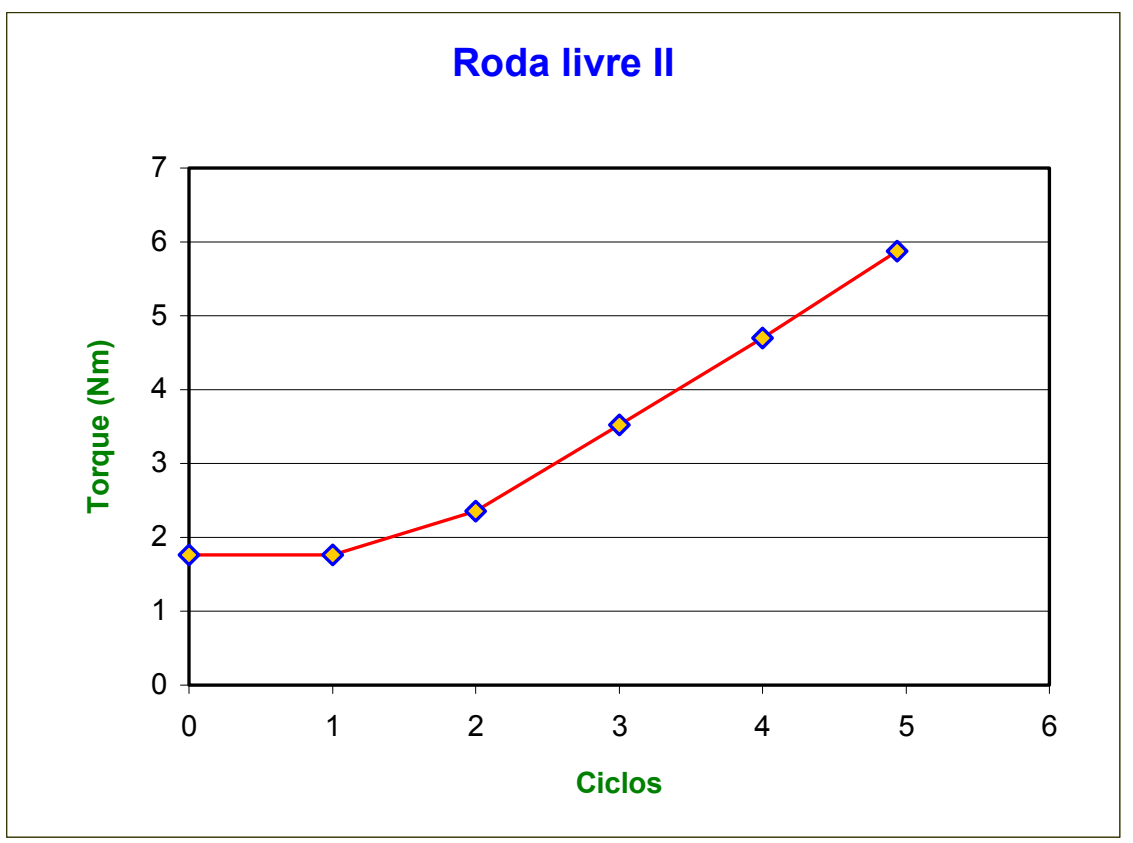

Figura 26. Torque gerado na segunda roda livre.

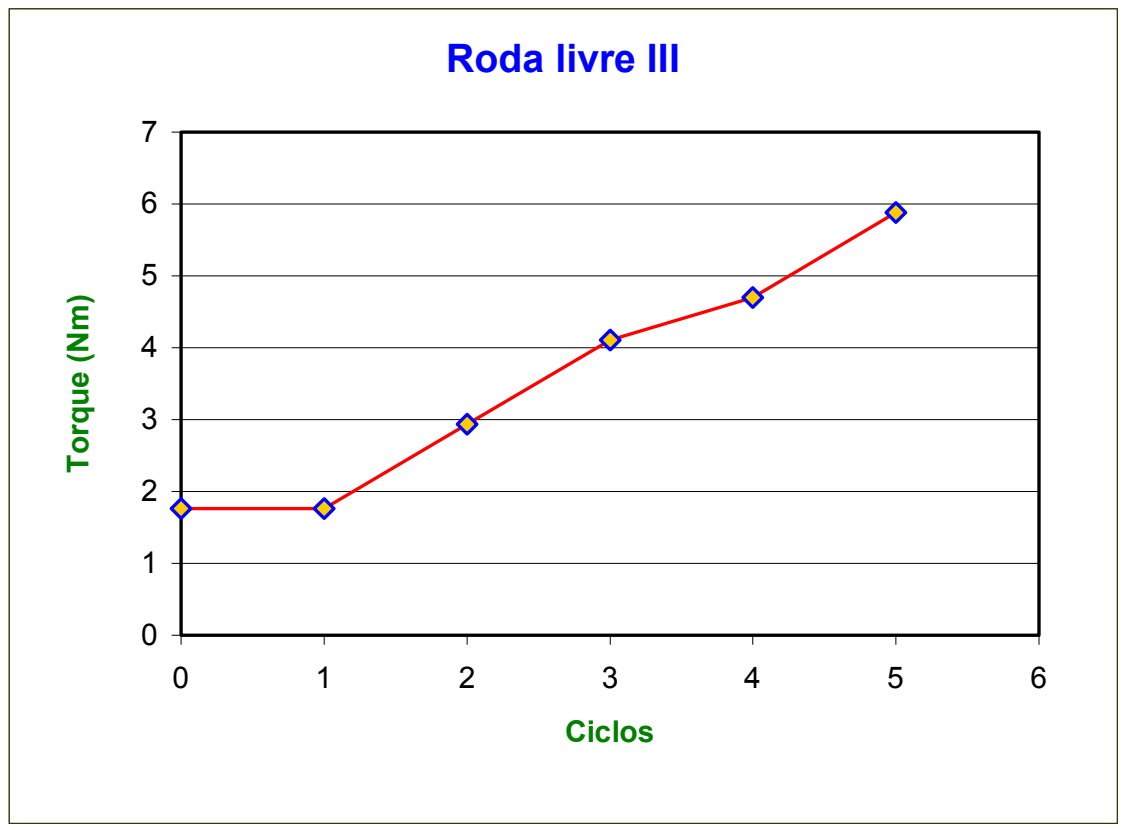

Figura 27. Torque gerado na terceira roda livre. 


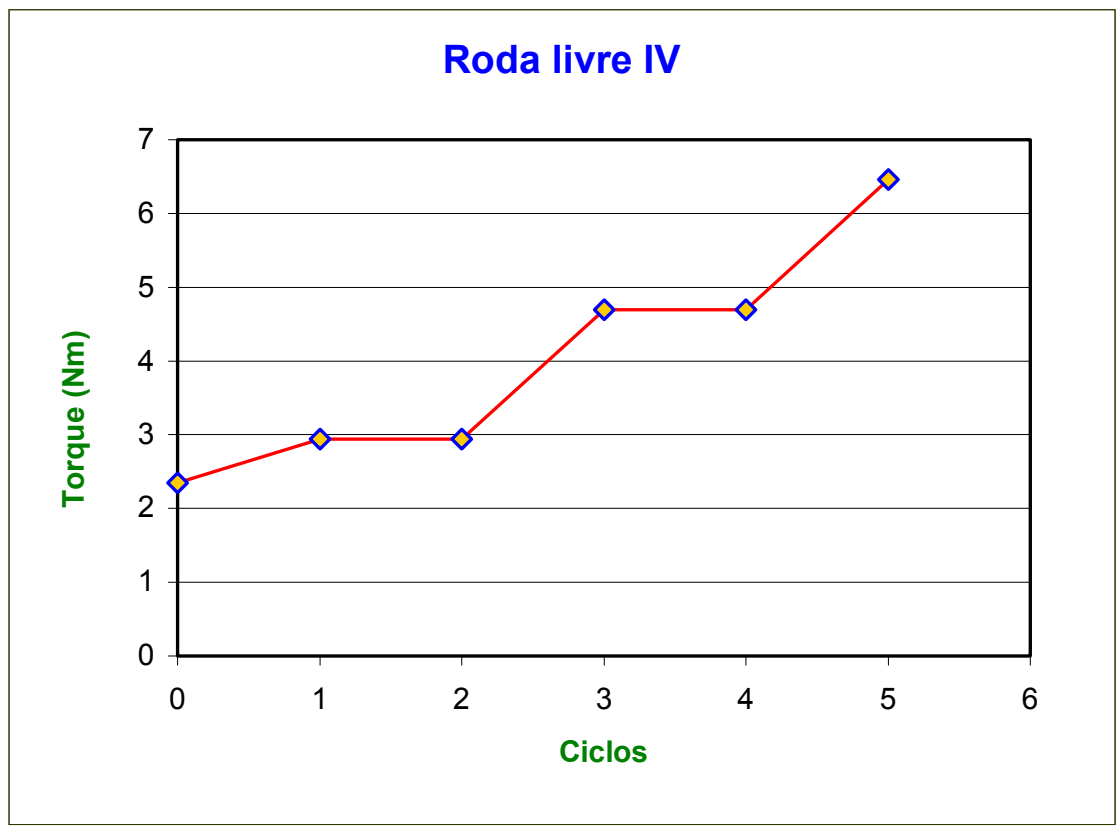

Figura 28. Torque gerado na quarta roda livre.

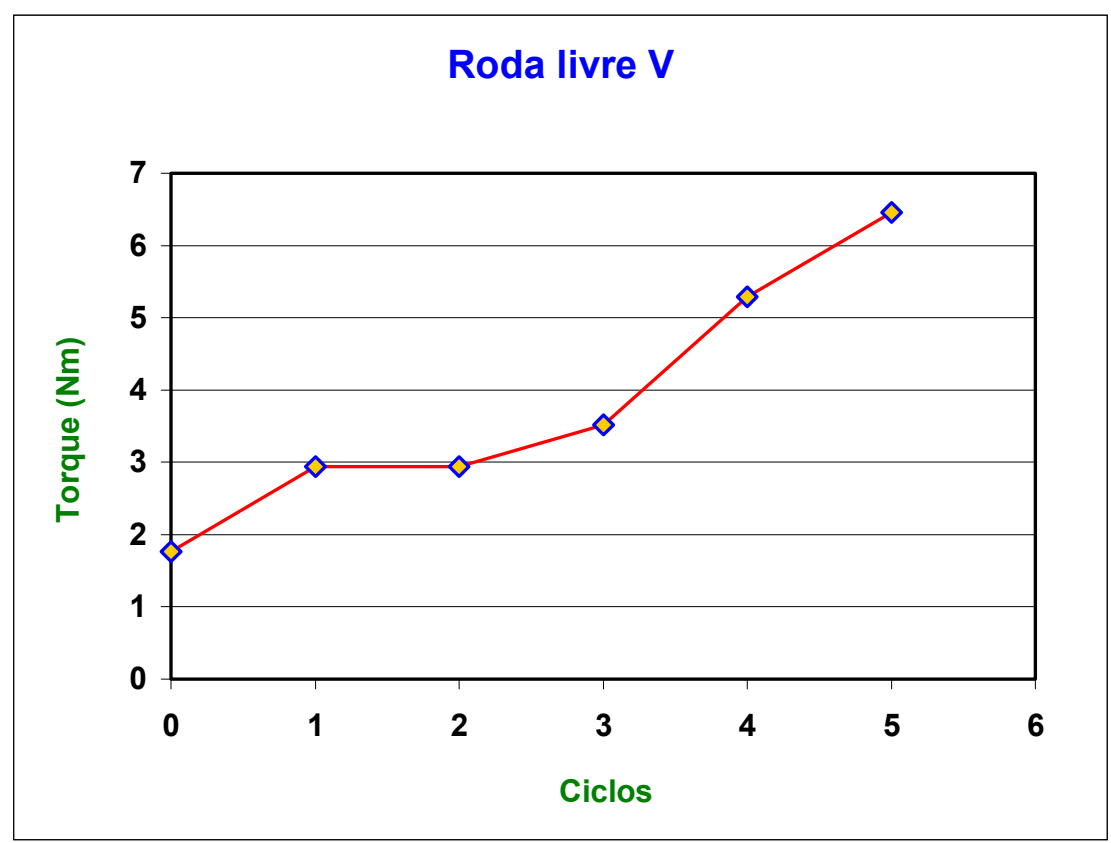

Figura 29. Torque gerado na quinta roda livre. 


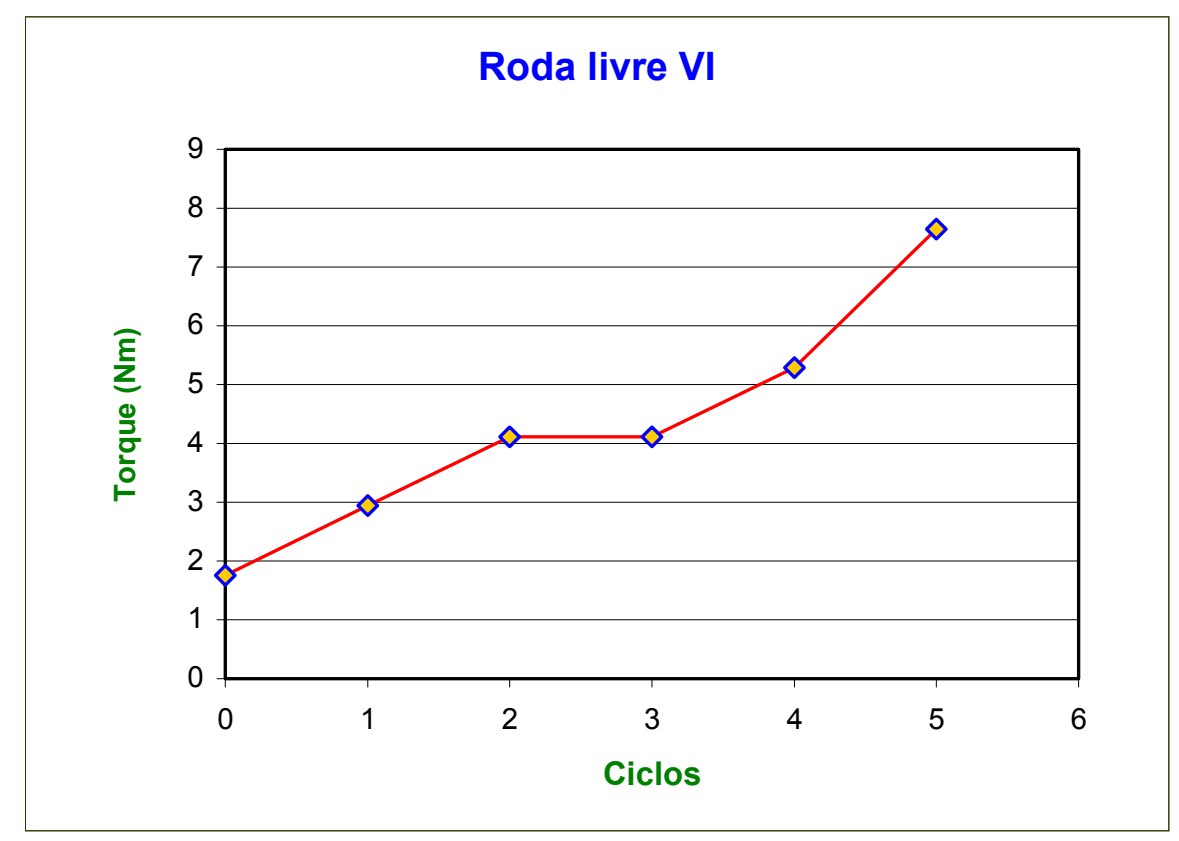

Figura 30. Torque gerado na sexta roda livre (menor).

\subsection{CALIBRAÇÃO ESTÁTICA DOS PEDAIS}

A figura a seguir apresenta os resultados da calibração estática dos pedais nas rodas dentadas que interligam os pedais ao eixo do sistema. 


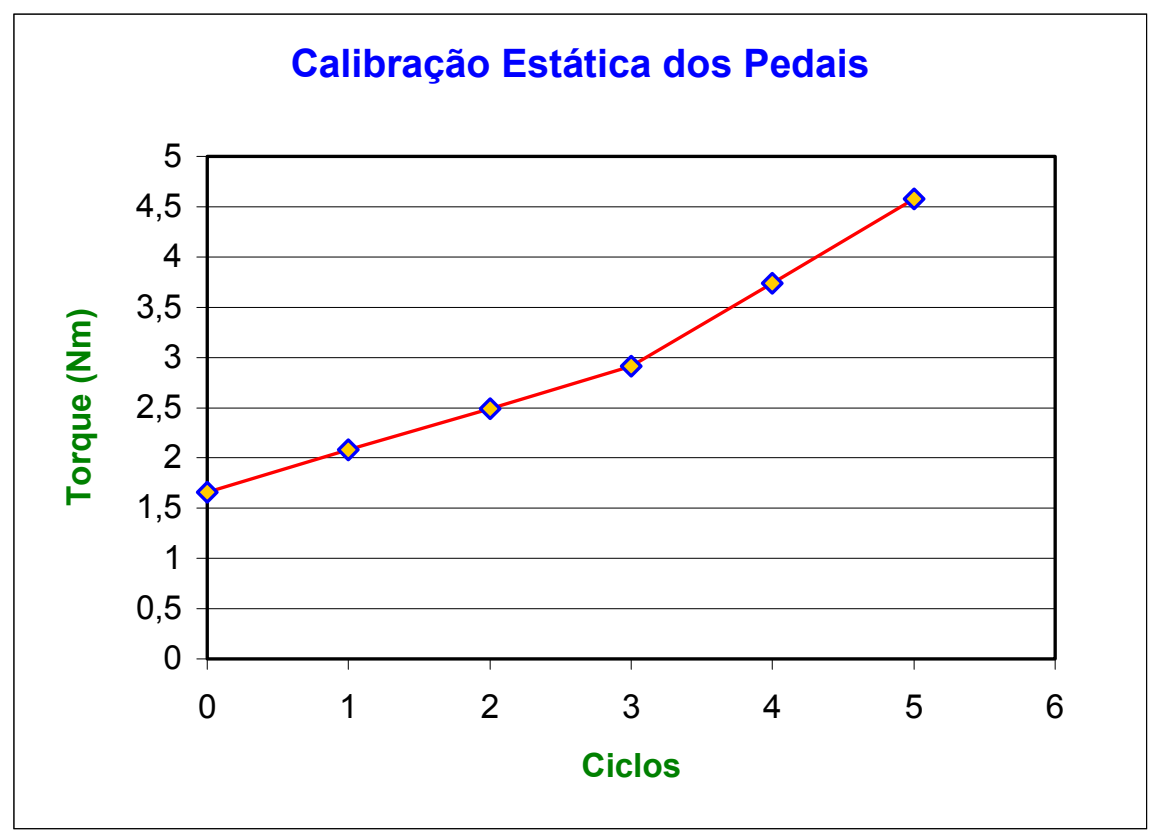

Figura 31. Calibração estática dos pedais.

\subsection{TESTE EM PESSOA NORMAL}

As avaliações dinâmicas do equipamento foram realizadas utilizando um indivíduo normal, saudável, para verificar as condições reais do aparelho durante o exercício.

\subsection{AVALIAÇÃO DINÂMICA DOS MANÍPULOS}

Todas as 6 rodas livres foram calibradas, sendo observado os valores registrados na ponte de telemetria a cada ciclo de carga, verificados durante o exercício dinâmico. 
A figura abaixo apresenta os valores da avaliação dinâmica dos manípulos na primeira roda livre (maior).

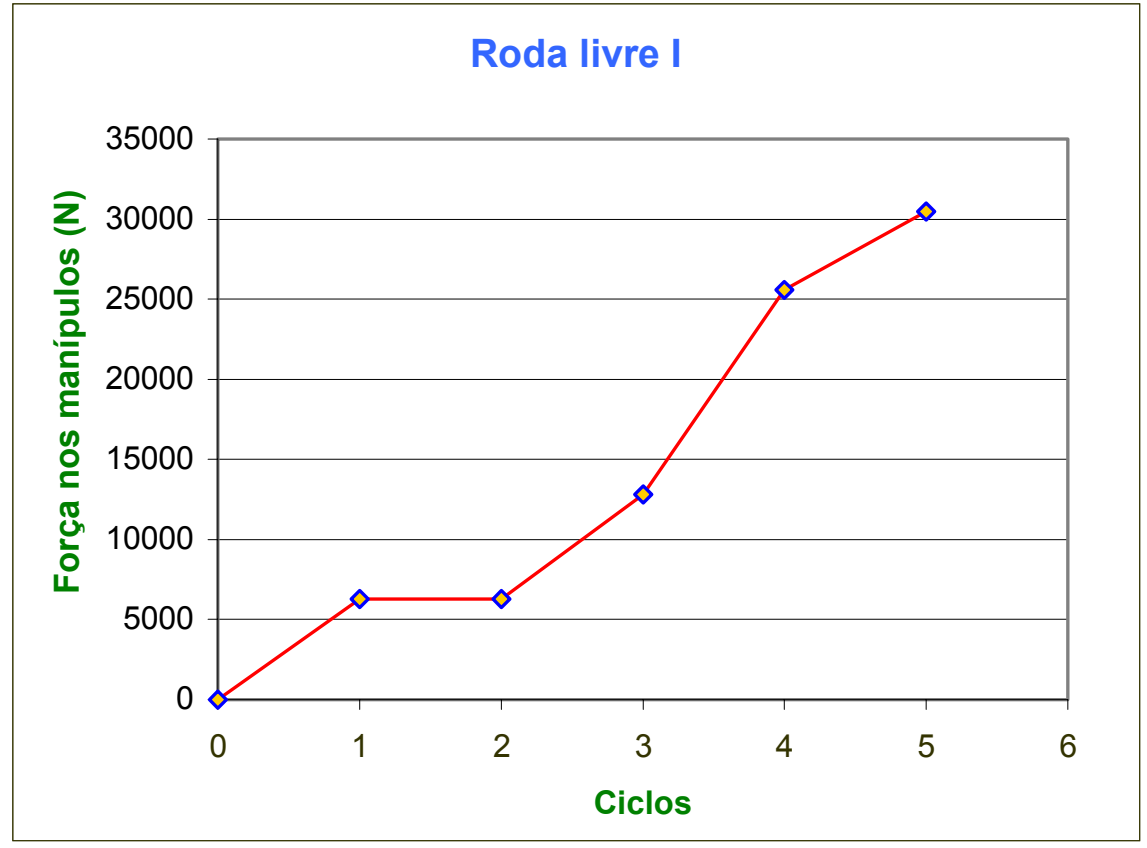

Figura 32. Força desenvolvida nos manípulos utilizando a primeira roda livre (maior).

A figura seguinte apresenta os valores da avaliação dinâmica dos manípulos na segunda roda livre. 


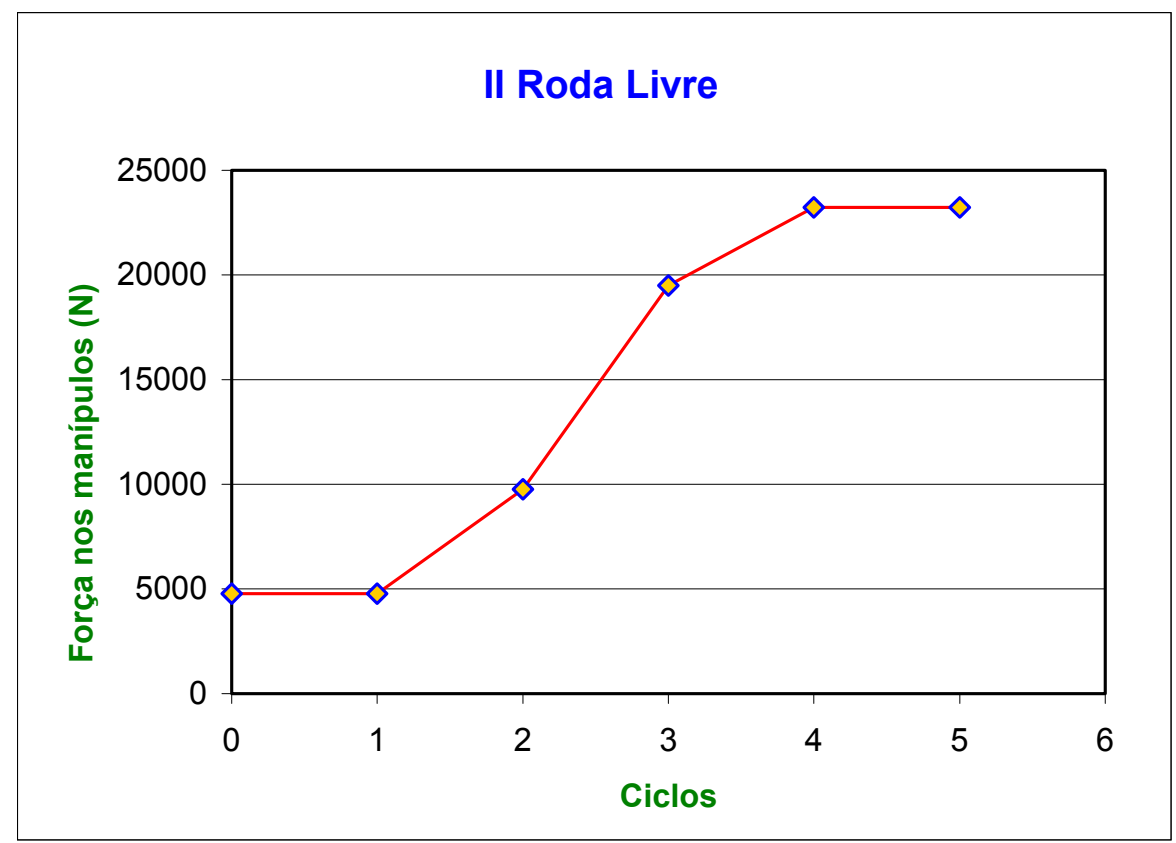

Figura 33. Força desenvolvida nos manípulos utilizando a segunda roda livre.

A figura a seguir apresenta os valores da avaliação dinâmica dos manípulos na terceira roda livre. 


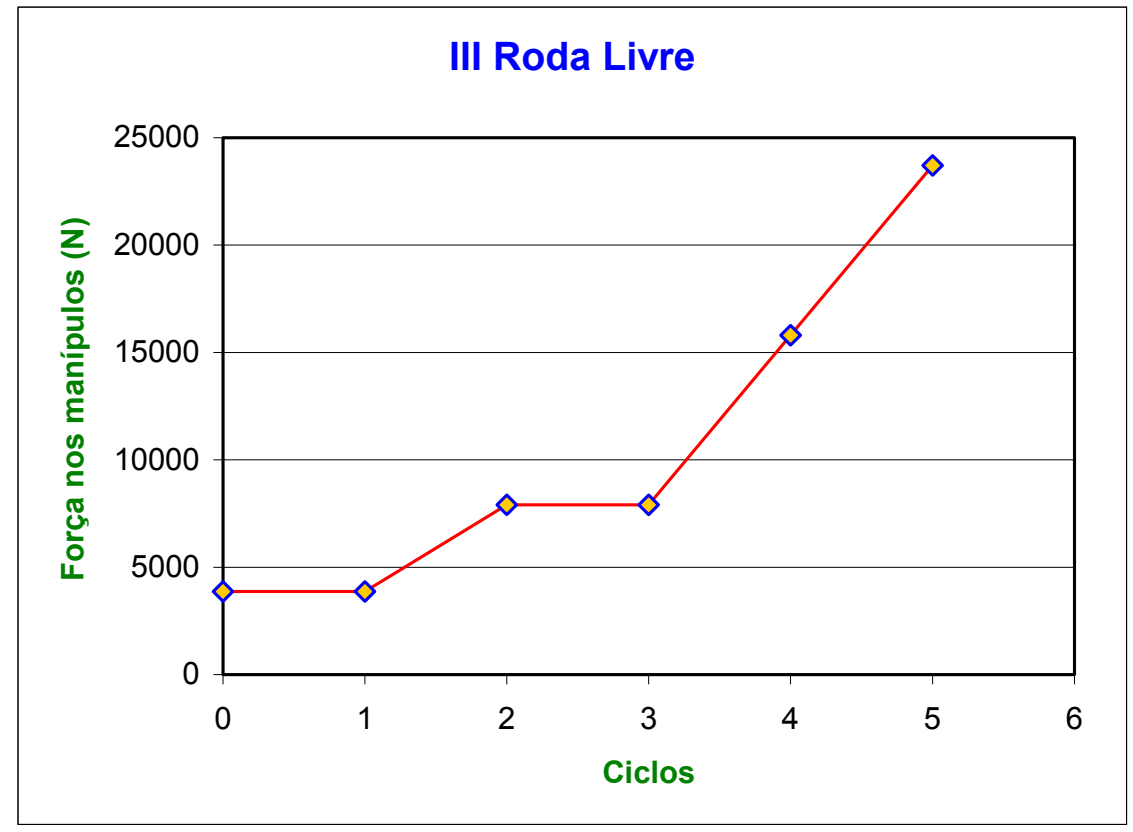

Figura 34. Força desenvolvida nos manípulos utilizando a terceira roda livre.

A figura a seguir apresenta os valores da avaliação dinâmica dos manípulos na quarta roda livre. 


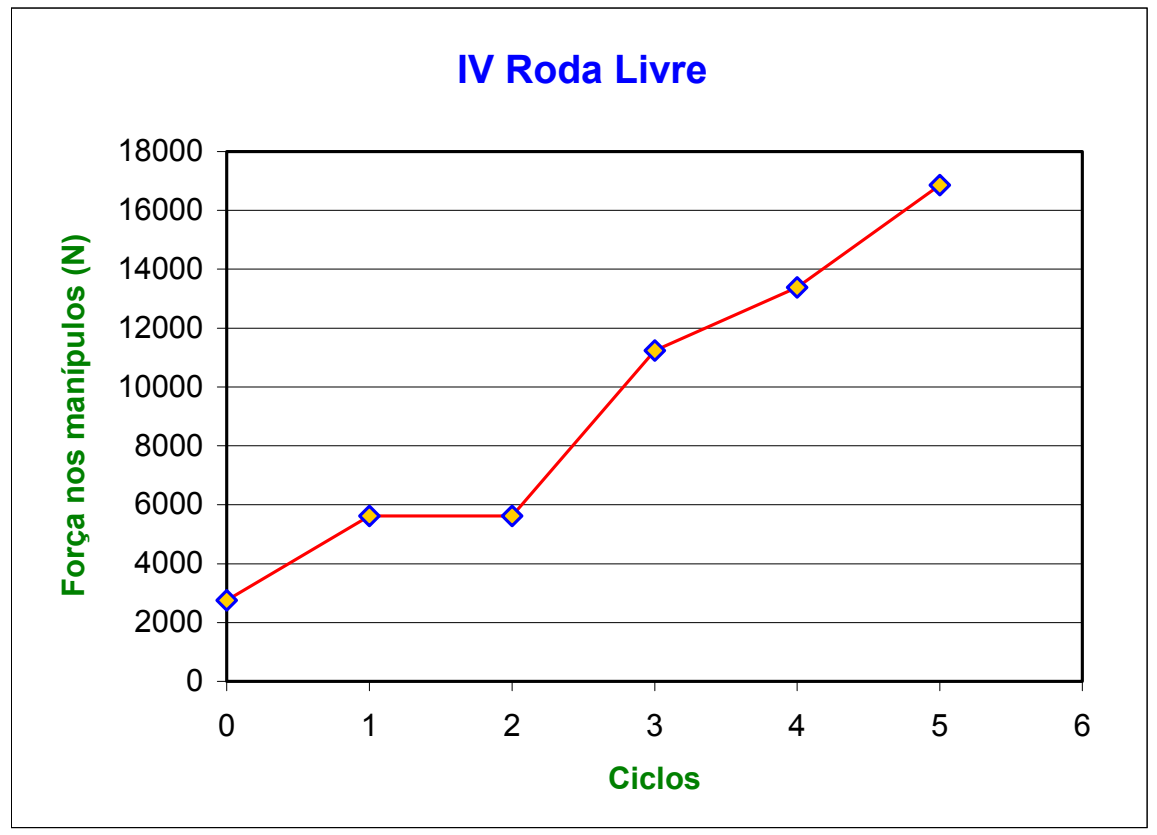

Figura 35. Força desenvolvida nos manípulos utilizando a quarta roda livre.

A figura a seguir apresenta os valores da calibração dinâmica dos manípulos na quinta roda livre. 


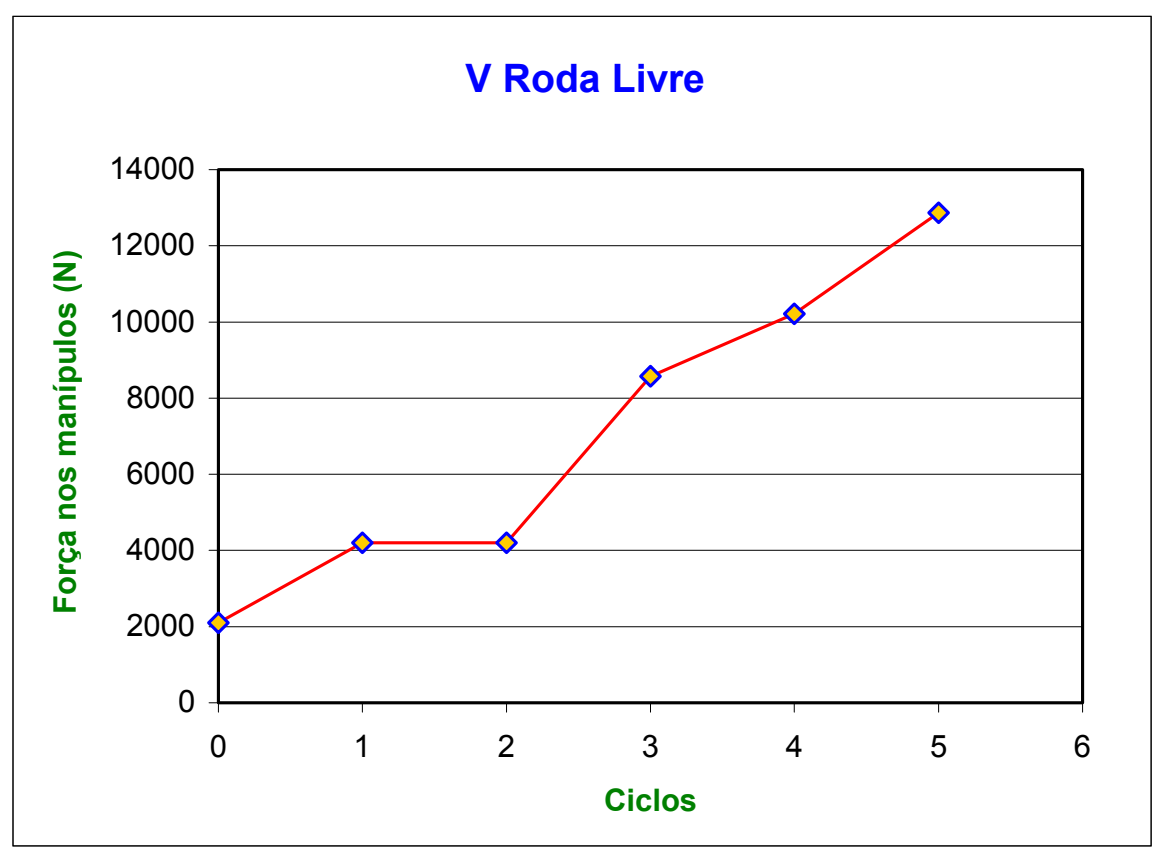

Figura 36. Força desenvolvida nos manípulos utilizando a quinta roda livre.

A figura seguinte apresenta os valores da avaliação dinâmica dos manípulos na sexta roda livre. 


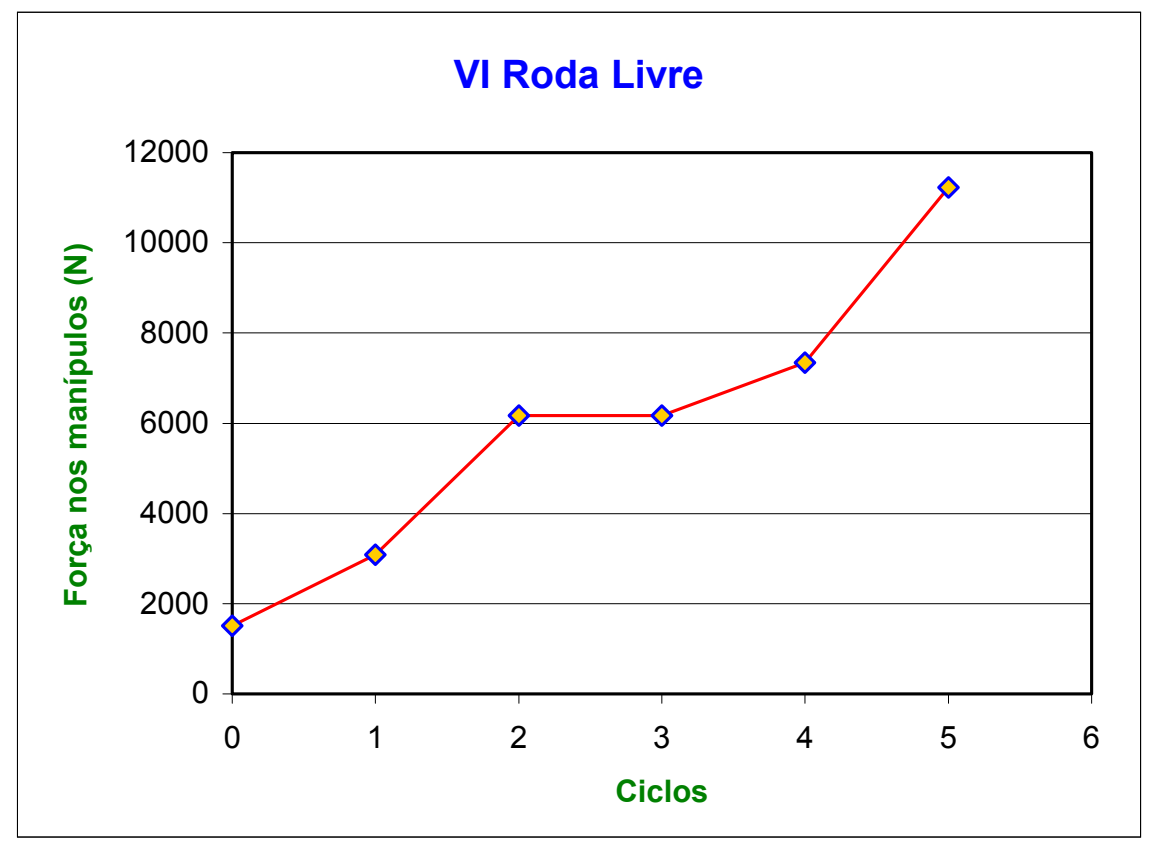

Figura 37. Força desenvolvida nos manípulos utilizando a sexta roda livre (menor).

\subsection{AVALIAÇÃO DINÂMICA DOS PEDAIS}

Para esta avaliação o torquímetro foi colocado do outro lado do disco, permanecendo assim, ligado aos pedais. 
A figura abaixo apresenta os valores da avaliação dinâmica dos pedais registrados na ponte de telemetria.

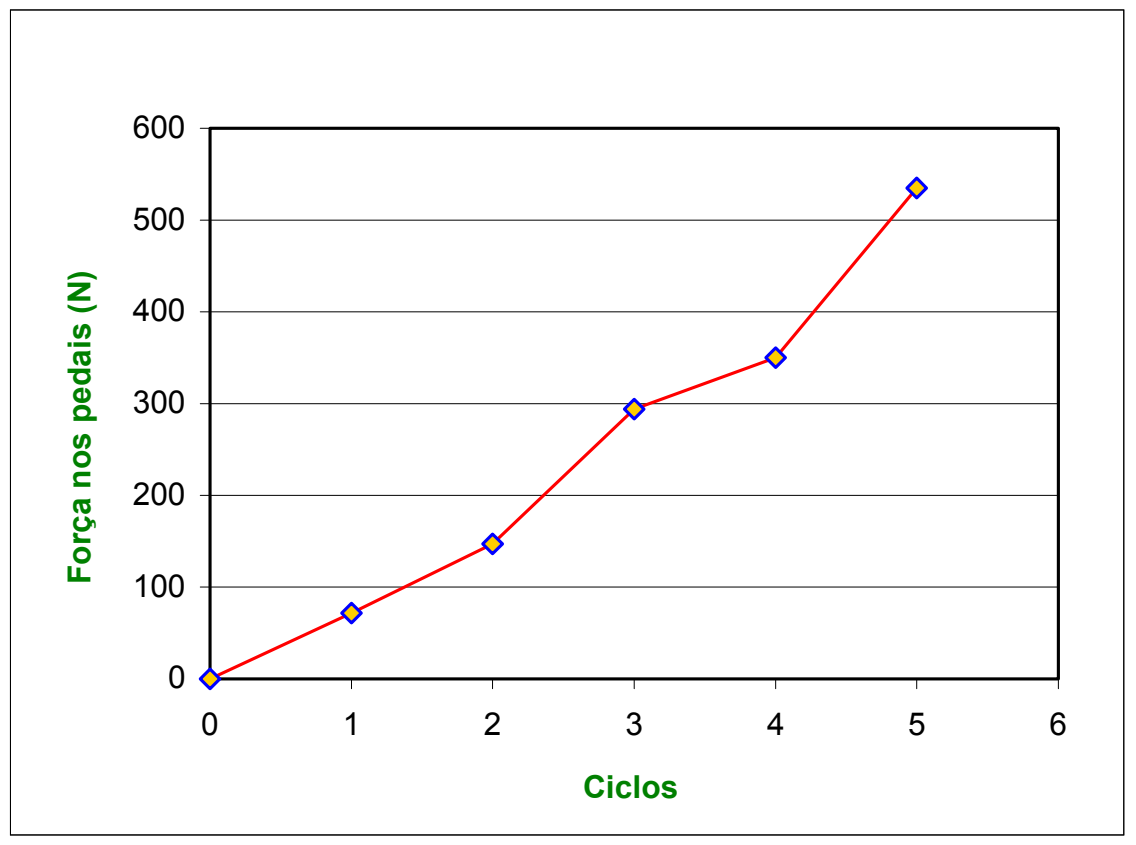

Figura 38. Avaliação dinâmica dos pedais. 
4. DisCUSSÃO 
O ciclo ergômetro convencional e posteriormente o ciclo ergômetro de braço foram desenvolvidos para aumentar a mobilidade articular e tônus muscular, melhorar a função cardiorespiratória, ou seja, melhorar o condicionamento global dos indivíduos saudáveis ou com incapacidades.

O surgimento do ciclo ergômetro de braço significou um grande avanço no tratamento de pacientes com lesão medular.

Um estudo feito por Zwiren e Bar-Or (1975), mostra a diminuição da função cardiorespiratória em paraplégicos sedentários em comparação com atletas em cadeira de rodas. Os atletas em cadeira de rodas obtiveram o $\mathrm{VO}_{2}$ mais alto que sujeitos saudáveis e paraplégicos sedentários, mas não muita diferença para atletas saudáveis. Essa investigação concluiu que a fraqueza cardiorespiratória nos sujeitos paraplégicos pode ser superada com a implementação de um programa de exercício regular, diário, para a extremidade superior.

Um programa de treinamento por um período de 8 semanas, no mínimo, que envolva também flexibilidade e alongamento dinâmicos, produz um aumento significativo na resistência cardiovascular e aptidão física (BOLTON e MILLIGAN 1976).

Um teste mais extenso em ergômetro de cadeira de rodas foi usado por Wilde et al., (1981), para avaliar a "performance" do miocárdio durante este tipo de exercício. Os resultados indicaram uma relação linear entre a produção cardíaca e o consumo de $\mathrm{O}_{2}$.

Infelizmente o ergômetro de braço não é tão eficiente mecanicamente quanto à bicicleta ergométrica, quando comparados às mesmas cargas de trabalho. Foi amplamente observado nos experimentos que, a níveis máximos de exercício, o aumento do $\mathrm{VO}_{2}$ é de 15 a $25 \%$ maior no trabalho de perna que 
no de braço. Porém, no trabalho de carga submáximo o oposto é verdadeiro, a relação entre $\mathrm{VO}_{2}$ / trabalho de carga é essencialmente retilínea para trabalho de perna e curvilínea (acima ou abaixo) para trabalho de braço. No início do teste com trabalho submáximo, não existe muita diferença entre os dois modos de exercício, mas com o aumento do trabalho de carga, a VO2, capacidade ventilatória e taxa cardíaca são maiores para o trabalho de braços que para o de pernas, para qualquer carga determinada.

Mas quando se relaciona a taxa cardíaca com qualquer resposta do $\mathrm{VO}_{2}$, não existe diferença entre os dois modos de exercício.

Como resultado do uso de uma massa muscular menor no exercício de braço, a fadiga ocorre mais cedo, atingindo somente 50 a $60 \%$ da carga de trabalho máxima que o trabalho de perna pode atingir.

A freqüência respiratória também é facilmente afetada no ergômetro de braço pela freqüência do movimento de rotação, e como resultado, a sincronização da freqüência respiratória com a manivela ocorre a níveis muitos baixos. Acredita-se que o aumento da freqüência e diminuição do volume relativo pode afetar a circulação dos músculos do braço, conduzindo a uma fadiga precoce (VOKAC et al.,1975).

DiCarlo, (1986) propôs avaliar os efeitos do treinamento com ergômetro de braço na função cardiopulmonar e resistência funcional na propulsão de cadeira de rodas em oito voluntários com quadriplegia secundária à lesão cervical (Figura 39), com idade de 18 a 30 anos, que não apresentavam problemas cardíacos, ou qualquer contra- indicação ao teste de treinamento e que não tivessem participado de treinamento aeróbico durante o período de seis meses.

A amostra de sujeitos era restrita a indivíduos com deficiência por, no mínimo 2 anos, de forma que os efeitos da lesão medular já tenham sido estabilizados. Os sujeitos nas cadeiras de roda eram posicionados em frente a 
mesa de sustentação do ergômetro de braço, tendo suas mãos fixas às espumas dos pedais, por bandagens elásticas. Cada teste incluía um período de aquecimento, iniciando com uma resistência de $0,5 \mathrm{Kg}$, a uma taxa de 50 rpm por 2 minutos, seguido de um acréscimo de $0,5 \mathrm{Kg}$ e $10 \mathrm{rpm}$ a cada 2 minutos de treinamento, até a taxa de $80 \mathrm{rpm}$ ser alcançada. A resistência funcional era cronometrada ao final de 12 minutos sustentados na tarefa de propulsão da cadeira de rodas em um recinto fechado de $200 \mathrm{~m}$ até o sinal de parar. Este estudo demonstra um aumento significante na melhora da função cardiopulmonar e resistência funcional ocorridas à intensidades de treinamento muito baixas, contribuindo também na execução das atividades de vida diária para esta população de pacientes.

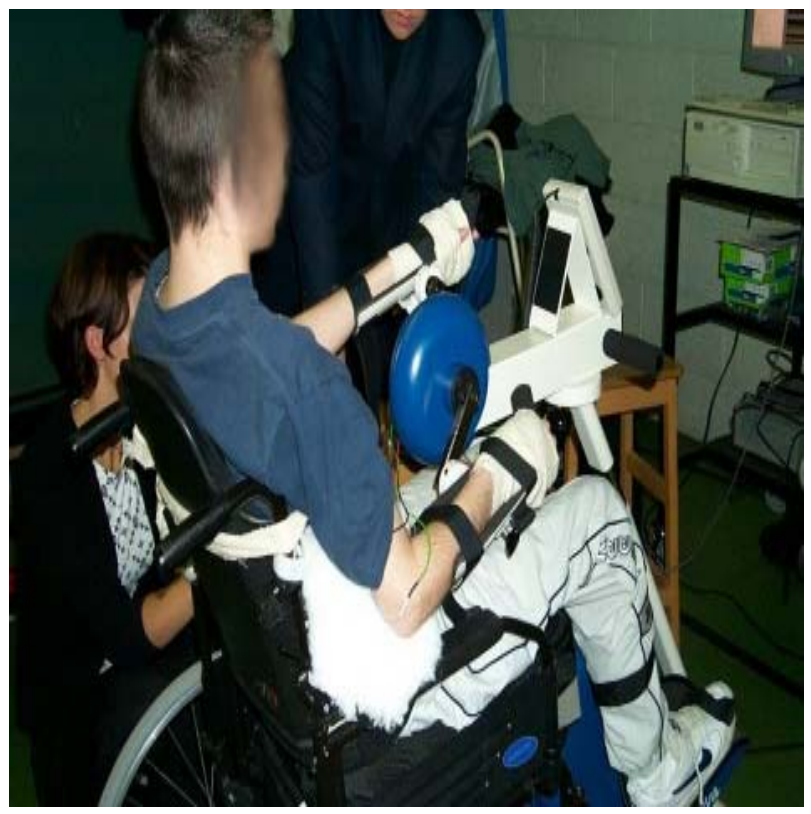

Figura 39. Paciente tetraplégico exercitando em ergômetro de braço com estimulação elétrica. Fonte: Disponível em: <fesnet.eng.gla.ac.uk/CRE/gollee.doc>.Acesso em: 12 out. 2003. 
Em um estudo sobre as respostas fisiológicas relacionadas à idade e sexo para o exercício no ergômetro de braço, BALADY et al.,(1990) avaliaram 80 voluntários saudáveis. Os sujeitos foram remanejados em 2 grupos, o primeiro, classificado como grupo de estudo, era composto de 60 sujeitos, sendo 30 mulheres e 30 homens, subdivididos de acordo com a idade, 20 a 29 , 30 a 39 e 40 a 59 anos respectivamente.Cada subgrupo formado por 10 homens e 10 mulheres. O segundo grupo, de validação, era formado por 20 sujeitos, 15 homens e 5 mulheres, com idade entre 30 a 35 anos, no qual se equacionava $\mathrm{O}_{2}$ consumido a cada estágio do teste no ergômetro de braço, derivados dos dados obtidos do grupo de estudo. $O$ teste iniciava-se com uma potência de $10 \mathrm{~W}$, acrescidos a cada 2 minutos, a uma velocidade de 75 a 80 rpm, e finalizavam-se quando os sujeitos chegavam à exaustão. Os dados resultantes demonstram que os sujeitos alcançaram $90 \%$ da taxa cardíaca máxima, e que os homens alcançaram uma produção de força, pico de $\mathrm{VO}_{2}$ maiores que as mulheres.Os voluntários mais velhos alcançaram potências mais baixas que os mais novos, podendo estar relacionado às diferenças no condicionamento e massa muscular. Estes dados provêem informações adicionais referentes às respostas fisiológicas para homens e mulheres saudáveis de várias idades, servindo como meio de reabilitação clínica do braço e reabilitação cardíaca.

Sawka et al., (1980) compararam as respostas metabólicas e circulatórias para o exercício em ergômetro de braço e ergômetro de cadeira de rodas. Participaram deste estudo 7 pacientes dependentes de cadeira de rodas e 10 voluntários saudáveis. O teste foi realizado em ambos equipamentos, a níveis de potência de 30, 90, 150 e $210 \mathrm{kpm} \cdot \mathrm{min}^{-1}$, onde foram avaliados o $\mathrm{VO}_{2}$, a ventilação pulmonar, o $\mathrm{O}_{2}$ equivalente a ventilação $\left(\mathrm{VE} . \mathrm{VO}_{2}{ }^{-1}\right)$, produção cardíaca, pulsação, diferenças de oxigenação arteriovenosa, taxa cardíaca, pressão arterial sistólica e produção de taxa de pressão a cada produção de força. Os resultados demonstraram que com exceção do VE. $\mathrm{VO}_{2}^{-1}$ 
e oxigenação arteriovenosa, cada variável tende ao aumento dos índices com o acréscimo de força. As demais variáveis apresentaram índices mais altos para o ergômetro de cadeira de rodas que para o ergômetro de braço, sugerindo que o teste de exercício no ergômetro de cadeira de rodas é mais estrênuo.

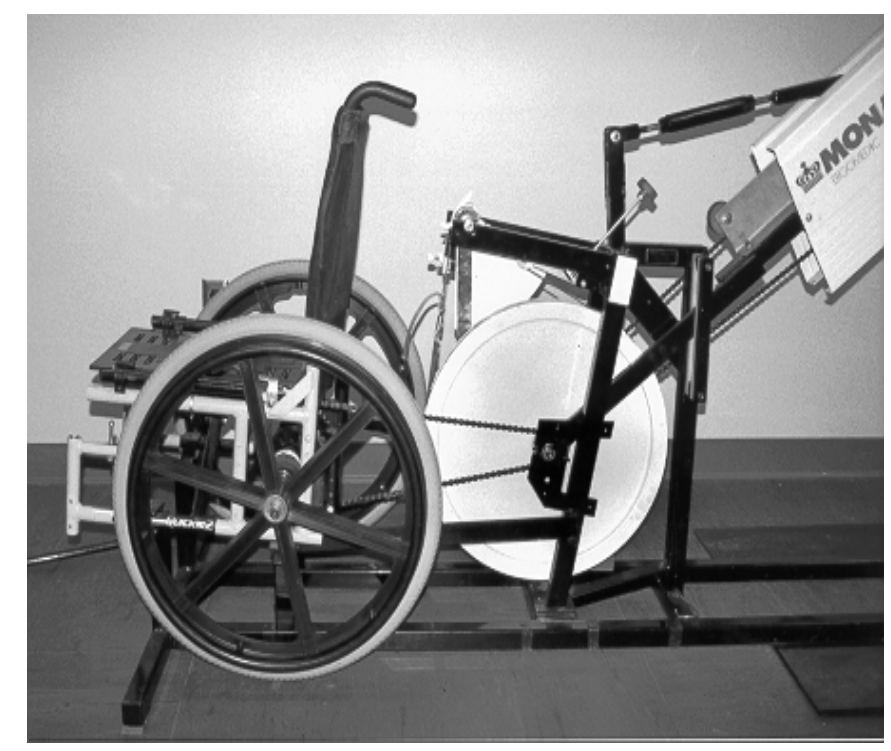

Figura 40. Ergômetro de cadeira de rodas (wheelchair ergometer). Sarah Morrisson. Guidelines for the Clinician for development of Fitness Programs for individuals with spinal cord injury. Dísponível em:www.vard.org/mono/sci/scimorri.htm. Acesso em: 04/junho de 2003.

Estudando os efeitos do exercício de longa duração para braços e pernas, PRICE et al., (2000) compararam 31 sujeitos, sendo 9 atletas competidores de cadeira de rodas, 12 atletas corredores de longa distância e 10 indivíduos saudáveis para controle. Este estudo buscou determinar se o exercício de longa duração com membros inferiores equivale ao condicionamento de indivíduos treinados com exercício dinâmico de braços. Os resultados demonstraram que os 2 grupos treinados atingiram taxas de 
trabalho máximas mais altas no ergômetro de braço, e taxas similares de $\mathrm{VO}_{2}$, comparados com o grupo controle.

Discussão 64

Os atletas de cadeira de rodas tiveram o volume e massa do ventrículo esquerdo aumentados, confirmados na ecocardiografia. Os corredores obtiveram o índice da taxa cardíaca mais baixa, comparados com os atletas de cadeira de rodas e sujeitos controle.

Estudos de BALADY, et al., (1986) e MILES et al., (1989), confirmaram que a qualquer pico de trabalho submáximo, o pico cardíaco e a pressão arterial sistólica serão maiores para exercício de braços, somente o $\mathrm{VO}_{2}$ será maior para o exercício de pernas.

Outros exercícios envolvendo os membros inferiores com o uso de esteiras, e os membros superiores com a bicicleta de braço ou ambos com o ergômetro de braços e pernas revelam que existem diferenças na relação entre a porcentagem da taxa cardíaca máxima e porcentagem do $\mathrm{VO}_{2}$ máx em exercícios para jovens (Londeree et al.,1995) e homens idosos (Aminoff et al., 1998). Porém, as respostas da taxa cardíaca ao exercício são afetadas pelo volume sanguíneo central, atividade simpática e também influenciadas pela massa muscular envolvida no exercício (Ray et al., 1993 e Van Lieshoult et al., 2001).

O exercício prolongado é geralmente usado para treinamento aeróbico dos grupos musculares de membros inferiores, porém o exercício físico prolongado para membros superiores representa grande interesse para várias populações com necessidades especiais, incluindo atletas (nadadores, esquiadores, remadores) e indivíduos com incapacidades de membros inferiores.

As respostas fisiológicas ao exercício prolongado durante 60 minutos contínuos foram comparadas por Pimental et al., (1984), para o exercício com a bicicleta ergométrica e a bicicleta de braço, separadamente. Participaram deste estudo nove voluntários saudáveis, com média de idade de $22 \pm 3$ anos, altura de 1,72 $\pm 8 \mathrm{~cm}$ e peso $71,4 \pm 6,9 \mathrm{Kg}$. Foram realizados testes de 
intensidades submáxima e máxima, ambas na bicicleta de braço e bicicleta ergométrica. Os dados obtidos mostraram que o exercício de braço pode ser Discussão 65

sustentado a $60 \%$ do pico de produção de $0_{2}$ por 60 minutos, apresentando respostas similares para as trocas de lactato e volume de plasma durante 0 exercício de pernas às mesmas intensidades relativas. Os dados do eletrocardiograma provaram que as taxas cardíacas são mais baixas para o exercício com a bicicleta de braço que com o exercício na bicicleta ergométrica, onde as prescrições de programas de exercício para membros inferiores, baseadas na taxa cardíaca máxima podem precisar de modificações para o exercício de membros superiores.

Os exercícios de resistência aumentam o volume sanguíneo e o metabolismo celular, melhoram a vascularização, resultando no aumento do $\mathrm{VO}_{2}$ máximo (JOCHHEIM, et al., 1973; SCRUTON 1979).

Em outro estudo, Wicks et al.,(1978) compararam a execução com potência máxima em ergômetro de cadeira de rodas com o ciclo ergômetro de braço com cargas de trabalho progressivas, em multiestágios para indivíduos paraplégicos. O resultado desta investigação indica que a eficiência mecânica da performance na propulsão do ergômetro de cadeira de rodas é significantemente diferente da do ergômetro de braço.

Outra pesquisa realizada por Marincek e Valencic (1978) no qual foi observada a eficiência da propulsão do braço, nos modos sincrônico e alternado, constatou-se que paraplégicos que executavam funções normais de membros superiores, eram melhor com o modo alternado de propulsão de braço que com o modo sincrônico. A razão para isso é que o movimento acontece somente no plano transversal, no eixo axial do tronco, evitando a flexão da coluna como acontece na propulsão sincrônica.

Outros trabalhos indicam que a habilidade em executar o exercício na ergométrica de cadeira de rodas diminui com a idade (SAWKA et al., 1981), similar para os resultados de populações saudáveis em geral. 


\subsection{RELEVÂNCIA DO CICLO ERGÔMETRO PARA MEMBROS SUPERIORES E INFERIORES}

Considerando que a maioria das clínicas de reabilitação física possui uma bicicleta ergométrica (de uso restrito a membros inferiores) e que, o ciclo ergômetro para membros superiores é ainda pouco comercializado e de custo elevado, avaliou-se a necessidade de um equipamento que suprisse ambas necessidades, poupando custos e tempo de tratamento despendido pelos pacientes.

O ciclo ergômetro para membros superiores e inferiores poderá contribuir de forma substancial no tratamento de indivíduos com incapacidades, pois permite o movimento dos membros superiores sempre de forma ativa, e dos inferiores, ativa ou passivamente, conforme as necessidades de cada indivíduo, ampliando o leque de benefícios de pacientes em fase de reabilitação, em especial aos paraplégicos que impossibilitados de pedalar, nunca poderiam praticar este exercício dinâmico.

Com este equipamento, estariam mobilizando seus membros inferiores hipotônicos através dos superiores, realizando uma automobilidade articular, melhorando a irrigação tecidual e o retorno venoso, além do estímulo psicológico, que entre tantos benefícios, merecem importância.

Sua utilidade será ampla na reabilitação, principalmente nos setores de cardiologia, pneumologia, ortopedia e traumatologia, neurologia, desportiva, e no condicionamento físico de sedentários e atletas. 



\section{CONCLUSÕES}

Conclusões 68

Diante do objetivo proposto e dos resultados obtidos no presente trabalho, conclui-se que o equipamento desenvolvido é capaz de realizar movimentos independentes de rotação dos membros inferiores ou superiores, isoladamente ou de forma conjunta, sob condições de carga mecânica determinadas, permitindo potencializar e ampliar o leque de benefícios gerados pelos aparelhos isolados.

Considerando ser de baixo custo e de tecnologia nacional, o desenvolvimento do ciclo ergômetro para membros superiores e inferiores se torna viável comercialmente.

$\mathrm{Na}$ qualidade de proposição para trabalhos futuros, sugerimos a incorporação de um sistema de medida de torque (torquímetro) acoplado a um sistema de aquisição de sinal e apresentação de informações em "display", de forma a ser possível a obtenção de dados de interesse biomecânico (torque, força, energia, etc) durante a utilização do equipamento. 



\section{REFERÊNCIAS BIBLIOGRÁFICAS}

Referências Bibliográficas 70

ANDREW, HARRELSON, WILK (1998). Reabilitação Física das Lesões Desportivas. $2^{\circ}$ Edição. Ed. Guanabara Koogan S. A., 504 p.

AMINOFF T., SMOLANDER J., KORHONEN O, LOUHEVAARA V. (1998). Prediction of acceptable physical work loads based on responses to prolonged arm and leg exercise. Ergonomics, v.41, p. $109-120$.

BALADY G. J., SCHICK E. C., WEINER D. A., RYAN T. J. (1986). Comparison of determinants of miocardial oxygen consumption during arm and leg exercise in normal persons. American Journal Cardiology, v. 57, p. 1385-87.

BALADY G. J., WEINER D. A., ROSE L, RYAN T. J., ERARIO M. (1990). Physiologic responses to arm ergometry exercise relative it age and gender. Journal American College of Cardiology, v. 16, p.130-5.

BEARSY H. J. (1947). Physical Medicine in Prevention and Treatment of Athetic Injuries. Journal Am. Med. Assn., v. 135, p. 613-16.

BOLTON B, MILLIGAN T. (1976). The effects of a systematic physical fitness program on clients in a comprehensive rehabilitation center. Am. Correct. Therapy Journal, v. 30, p. 41-46.

BORBERT A. C. (1960). Physiological comparison of three types of ergometry. J. Appl. Physiol, v.15, n. 6, p. $1007-1014$.

BOSTOM AG, BATES E, MAZZARELLA N, BLOCK E, ADLER J. (1987). Ergometer modification for combined arm-leg use by lower extremity amputees in cardiovascular testing and training. Arch. Phys Med Rehabil, v. 68, p. 244-47.

BRENES G., DEARWATER S., SHAPERA R, LAPORTA RE., COLLINS E. (1986). High density lipoprotein cholesterol concentrations in physically active and sedentary spinal cord injured patients. Arch. Phys. Med. Rehabil, v. 67, p. 445-50. 
BRESSEL E., BRESSEL M., MARQUEZ M., HEISE G. D. (2001). The effect of handgrip position on upper extremity neuromuscular responses to arm cranking exercise. Journal of Electromyography and Kinesiology, v. 11, p. 291 - 298.

Referências Bibliográficas 71

CEFISE - Centro de Estudos da Fisiologia do Esporte, 2003. Disponível em: < www. cefise.com.br>. Acesso em: 06/09/03.

CLAUSEN JP, KLAUSEN K, RASMUSSEN B, et al., (1973). Central and peripheral circulatory changes after training of the arms or legs. Am. Journal Physiol., v. 225, p. 675-82.

COWELL LL., SQUIRES WG., RAVEN PB. (1986). Benefits of aerobic exercise for the paraplegic: A brief review. Med. Sci. Sports Exerc, v. 18, p. 501-08.

DAWSON C. D. (1953). An Intensive Exercise Program for use in Knee Surgery and phatology. Archives Phys. Med., v.34, p. $730-755$.

DiCARLO S. E. (1988). Effect of arm ergometry training on wheelchair propulsion endurance of individuals with quadriplegia. Physical Therapy, v. 68, p.40-4.

DiCARLO S. E., SUPP MD, TAYLOR HC. (1983). Effect of arm ergometry training on physical work capacity of individuals with spinal cord injuries. Physical Therapy, v. 63, p. 1104-107.

DiCARLO S.E. (1986). Effect of arm ergometry training on wheelchair propulsion endurance of individuals with quadriplegia. Physical Therapy, v. 14, p. $40-4$.

FARDY, P. S., D. WEBB, H.K. HELLERSTEIN. (1977). Benefits of arm exercise in cardiac rehabilitation. Physician Sports Med, v. 5.

GASS GC, CAMP EM. (1979). Physiological characteristics of trained Australian paraplegic subjects. Med. Science Sports, v. 11, p. 256-59. 
GLASER RM, SAWKA M, WILDE S, WOODROW B, SURYAPRASED A. (1981). Energy cost and cardiopulmonary responses for wheelchair locomotion and walking on tile and on carpet. Paraplegia, v. 19, p. 220-226.

Referências Bibliográficas 72

GOLLEE H., HUNT K. J., COUPAUD S., MCLEAN A. N., FRASER M. H. An apparatus for Fes - assisted arm cranking exercise in tetraplegia. Disponível em:< http://fesnet.eg.gla.ac.uk/CRE/gollee.doc $>$. Acesso em: 02/08/03.

HARMAN E., KNUTTGEN H. G., FRYKMAN P. (1987). Automated data collection and processing for a cycle ergometer. J. Appl. Physiol, v. 62, n. 2, p. 831-6.

História da Bicicleta (2003). Disponível em: < www.bikerzl.hpg.ig.com.br>. Acesso em: 12/04/03.

HJELTNES N, VOKAC Z. (1979). Circulatory strain in everyday life of paraplegics. Scand. Journal Rehabil. Med., v. 11, p. 67-73.

HOFFMAN M. D. (1986). Cardiorespiratory fitness and training in quadriplegics and paraplegics. Sports Med., v. 3, p. 312-30.

HOUTZ, S.J.; FISCHER, J. F. (1959). An Analysis of Muscle Action and Joint Excursion During Exercise on a Stationary Bicycle. The J. of Bone and Joint Surgery, v. 41-A, n. 1, Jan., p.123-31.

HULL M. L., JORGE M. (1985). A method for biomechanical analysis of bicycle pedalling. J. Biomechanics, v. 18, n. 9, p. $631-644$.

JOCHHEIM KA, STROHKENDL H. (1973). The value of particular sports of the wheelchair-disabled in maintaining health of the paraplegic. Paraplegia, v. 11, p. 173-178.

KENNETH H. P., PETER G. SNELL, JAMES S.G. (1987). Maximal response of wheelchair-confined subjects to four types of arm exercise. Arch. Phys. Med. Rehabil. v. 68, n. 1, Jan. 
KNUTSSON E., LEWENHAUPT-OLSSON E., THORSEN M. (1973). Physical work capacity and physical conditioning in paraplegic patients. Paraplegia, v. 11 , p. 205-16.

Referências Bibliográficas 73

LONDEREE B. R., THOMAS T. R., ZIOGAS G., SMITH T. D., ZHANG Q. (1995). \% $\mathrm{VO}_{2}$ máximo versus \% $\mathrm{HR}$ máx regressions for six modes of exercise. Med. Sci. Sports Exerc.,v 27, p. 458-461.

LOUDON J. K., CAGLE P. E., FIGONI S. F., NAU K. L., KLEIN R. M. (1998). A submaximal all-extremity exercise test to predict maximal oxygen consumption. Med. Sci. Sports Exerc., v. 30, p. $1299-1303$.

MARINCEK, CRT, VALENCIC V. (1978). Arm cycloergometry and kinetics of oxygen consumption in paraplegics. Paraplegia, v. 15, p. 178-185.

MARINHEIRO C. A. Desenvolvimento de Máquina de Movimentos Cíclicos para testes Biomecânicos (2003). São Carlos. Dissertação (mestrado)Interunidades Bioengenharia- EESC/FMRP/IQSC - Universidade de São Paulo, $51 \mathrm{p}$.

MILES D. S., COX M. H., BOZME J. P. (1989). Cardiovascular responses to upper body exercise in normals and cardiac patients. Med. Sci. Sports Exerc., v. 21, p. $126-31$.

NILSSON S., STAFF PH., PRUETT EDR. (1975). Physical work capacity and the effect of training on subjects with long standing paraplegia. Scan. J. Rehabil. Med., v 7, p. 51-6.

OSCAL LB. (1973). The role of exercise in weight control. Exerc. Sport Sci. Rev., v. 1, p. 103-23.

PAFFENBARGER RS, LAUGHLIN ME, GIMA AS, et al. (1970). Work activity in longshoremen as related to death from coronary heart disease and stroke. New Engl. Journal Med, v. 282, p. 1109-1114. 
PAFFENBARGER RS, HALE WE. (1975). Work activity and coronary heart mortality. New Engl. Journal Med., v. 292, p.545-550.

PETROFSKY J S H HEALTON, PHILLIPS C A. (1983). Outdoor bicycle for exercise in paraplegics and quadriplegics. Journal Biomed. Eng., v. 5, p. 292295. Referências Bibliográficas $\mathbf{7 4}$

PIMENTAL N., SAWKA M. N., BILLINGS D. S., TRAD L. (1984). Physiological responses to prolonged upper-body exercise. Medicine and Science in Sports and Exercise, v. 15, n. 4, p. 360-365.

POLLOCK ML, MILLER HS, LINNERUD AC, et al. (1974). Arm pedaling as an endurance training regimen for the disabled. Arch. Phys. Med. Rehabil., v. 55, p. 418-24.

POWERS S. K., BEADLE R. E., MANGUM M. (1984). Exercise efficiency during arm ergometry: effects of speed and work rate. J. Appl. Physiol, v. 56, n. 2, p. 495-99.

PRICE D. T., DAVIDOFF R., BALADY G. J. (2000). Comparison of cardiovascular adaptations to long-term arm and leg exercise in wheelchair athletes versus long-distance runners. Am. Journal of Cardiol, v.85, p. 9961001.

PRO II POWER TRAINER (2003). Disponível em: www.nouboundaries.tv/spirit.htm. Acesso em: 08/09/03.

RAY C. A., REA R. F., CLARY M. P., MARK A. L. (1993). Muscle sympathetic nerve responses to dynamic one-legged exercise: effect of body posture. Am. Journal Physiol.,v. 264 (Heart Circ. Physiol. 33): H1 - H7.

RESSL J, CHRASTEK J, JANDOVA R. (1977). Haemodynamic effects of physical training in essential hypertension. Acta Cardiol.( Brux), v. 32, 121-33.

SARAH A MORRISON. Guidelines for the Clinician for development of fitness programs for individuals with spinal cord injury. Disponível em: www.vard.org/mono/scimorri.htm . Acesso em: 04/06/03. 
Saratoga Exercise Products (2003). Disponível em:www.easypivot.com/saratoga/models/spiritfeatureschart.htm. Acesso em: 26/09/03.

SAWKA, MICHAEL N, GLASER R M, WILDE S W, von LUHRTE T C. (1980). Metabolic and circulatory responses to wheelchair and arm crank exercise. Journal Appl. Physiol., v. 49, n. 5, p. 784-788.

SAWKA MN, GLASER RM, LAUBACH LL, ALI-SAMKARI O, SURYAPRASAD A. (1981). Wheelchair exercise performance of the young middle-aged, and elderly. Journal Appl. Physiol., v. 50, p. 824-828.

SCRUTON J. (1979). Sir Ludwig Guttman: creator of a world sports movement for the paralysed and other disabled. Paraplegia, v. 17, p. 52-55.

Selecting and effectively using stationary bicycles (2003). Disponível em: www.acsm.org. Acesso em 21/06/03.

SENE M. O. Efeitos da Estimulação Elétrica Neuromuscular (EENM) sobre o Gasto Energético de Lesados Medulares (2003). Dissertação (mestrado)Programa de Pós-Graduação Interunidades em Bioengenharia EESC/IQSC/FMRP, Universidade de São Paulo, 106 p.

SMITH-PETERSEN M. N. (1939). Arthroplasty of the Hip. A new method. Journal Bone and Joint Surg., v. 21, p. 269-88.

van LIESHOUT J. J., POTT F., MADSEN P. L., van GOUDOEVER J., SECHER N. H. (2001). Muscle tensing during standing effects on cerebral tissue oxygenation and cerebral artery blood velocity. Stroke, v. 32, p. $1546-1551$.

VOKAC Z, BELL H, BAUTZ-HOLTER E, RODAHL K. (1975). Oxygen uptake/heart rate relationship in leg and arm exercise, setting and standing. Journal Appl. Physiology, v. 39, p. 54-59.

WICKS J. R. (1978). The use of multistage exercise testing with wheelchair ergometry and arm cranking in subjects with spinal cord lesions. Paraplegia, v. 15 , p. 252-261. 
WILDE SW, DANIEL MS, MILES J, DURBIN M, MICHAEL N, SAWKA A, SURYAPRASAD R, GATSHALL W, GLASSER R. M. (1981). Evaluation of myocardial performance during wheelchair ergometer exercise. Am. Journal Phys. Med., v. 60, p. 277-290.

ZWIREN L, BAR-OR O. (1975). Responses to exercise of paraplegics who differ in conditioning level. Med. Sci. Sports, v. 7, p. 94-98. 
